\title{
RÉGIMEN DE PROTECCIÓN Y CONSERVACIÓN DEL PATRIMONIO ARQUITECTÓNICO EN LA REPÚBLICA ARGENTINA. CRITERIOS DE TUTELA EN LA CIUDAD AUTÓNOMA DE BUENOS AIRES ${ }^{(*)}$
}

\author{
PROTECTION AND CONSERVATION REGIME OF ARCHITECTURAL HERITAGE IN THE ARGENTINE REPUBLIC. \\ PROTECTION CRITERIA IN THE AUTONOMOUS CITY OF BUENOS AIRES
}

\author{
SILVANA DANIELA BASILE ${ }^{[\star]}$ \\ (D) https://orcid.org/0000-0002-1825-4450 \\ silvana.basile@polimi.it \\ Politecnico di Milano (Italia) \\ Fecha de recepción: 3 de mayo de 2020 \\ Fecha de aprobación: 8 de agosto de 2020
}

\section{RESUMEN}

El problema del patrimonio -instrumento indispensable de conocimiento- y de su tutela revisten cada vez mayor importancia en el debate contemporáneo en cuanto testimonio identitario de formas de vida y de culturas, conscientes de que no es posible en la arquitectura garantizar el conocimiento de la cultura del pasado si no es conservando la materia que lo atestigua.

El presente artículo aborda el tema del régimen de protección y conservación del patrimonio arquitectónico en la República Argentina con el objetivo de analizar el desarrollo de los instrumentos de protección (políticas patrimoniales) a nivel nacional, Argentina, y principalmente a nivel local de la Ciudad Autónoma de Buenos Aires. Hace un análisis preliminar de la legislación existente, desde las primeras normativas de preservación hasta aquellas actualmente vigentes. Examina su desarrollo y sus límites, trazando la historia de las medidas adoptadas y evaluando la eficacia de las especificaciones técnicas que, aunque referidas a la situación argentina, adquieren un significado universal.

\section{PALABRAS CLAVE}

Ciudad Autónoma de Buenos Aires; tutela del patrimonio; conservación de bienes arquitectónicos

\begin{abstract}
The problem of heritage -an indispensable instrument of knowledge- and its protection are increasingly importance in the contemporary debate as an identity testimony of ways of life and cultures, this aware that it is not possible in architecture to guarantee knowledge of the culture of the past if it is not conserving the matter that testifies it.

The following article addresses the issue of the regime of protection and conservation of architectural heritage in the Argentine Republic with the aim of analyzing the development of protection instruments (heritage policies) at the national level, Argentina, and mainly at the local level of the Autonomous City of Buenos Aires. It makes a preliminary analysis of the state of existing legislation from the first preservation regulations to those currently in force. It analyze its development and its limits, by tracing the history of the tools adopted and evaluate the effectiveness of the technical specifications that, although referred to the Argentinian situation, acquire universal significance.
\end{abstract}

\section{KEYWORDS}

Autonomous City of Buenos Aires; heritage protection; conservation of architectural heritage

${ }^{*}$ ) El presente trabajo tiene como antecedentes la tesis doctoral en Conservación de Bienes Arquitectónicos, Politécnico de Milán (Politiche di conservazione e tutela dei beni architettonici nella città di Buenos Aires e prospettive di recupero per il barrio La Boca. Director de tesis: Prof. Amedeo Bellini) y el libro Politiche di tutela e conservazione del patrimonio architettonico nella Repubblica Argentina. La città di Buenos Aires. Sant'Arcangelo di Romagna, Italia: Maggioli Editore, 2013.

${ }^{(* *)}$ Arquitecta egresada de la Facultad de Arquitectura, Diseño y Urbanismo de la Universidad de Buenos Aires y de la Facultad de Arquitectura y Sociedad del Politécnico de Milán; Magister en restauración de monumentos egresada de la Escuela de Especialización en Restauración de Monumentos del Politécnico de Milán y Ph.D en Conservación de Bienes Arquitectónicos. Desempenó actividades como editora, investigadora y docente en la "Scuola Universitaria della Svizzera Italiana" (Suiza). Actualmente colabora en los cursos de Historia de la Arquitectura del Politécnico de Milán y trabaja como arquitecta en el Estudio de Arquitectura Christen (Lugano-Suiza). Ha publicado libros, varios artículos científicos en revistas y textos y presentado trabajos ante congresos nacionales e internacionales. 
devenir Vol. 7, N¹4, JULIO - DICIEMBRE 2020, PP. 131-154 - EsTudIOS I ISSN 2312-7562 | E-ISSN 2616-4949

UNIVERSIDAD NACIONAL DE INGENIERÍA, LIMA

doi: https://doi.org/10.21754/devenir.v7i14.974

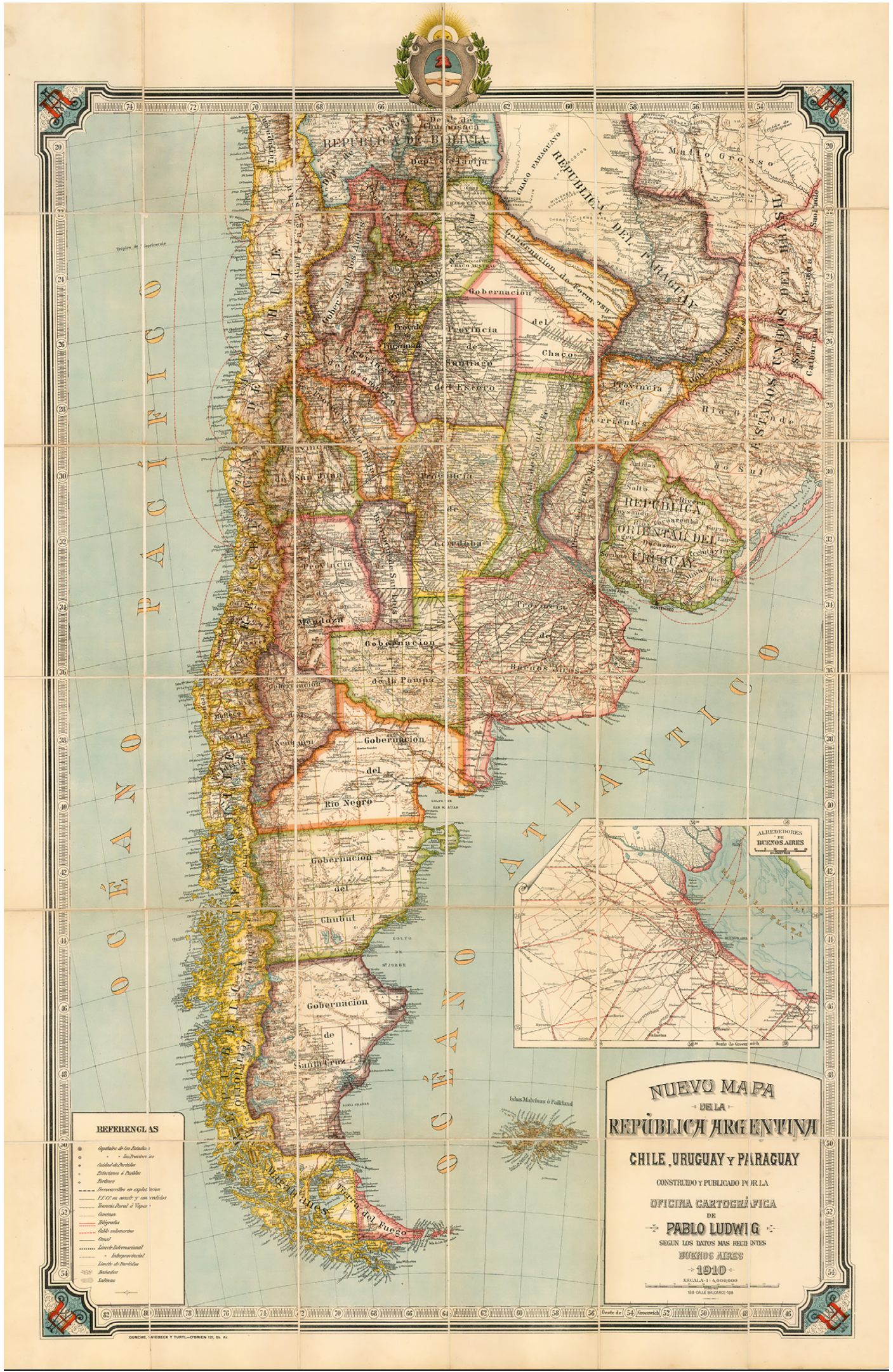

Figura 1. Mapa político de la República Argentina. David Rumsey Historical Map Collection, 2020. 


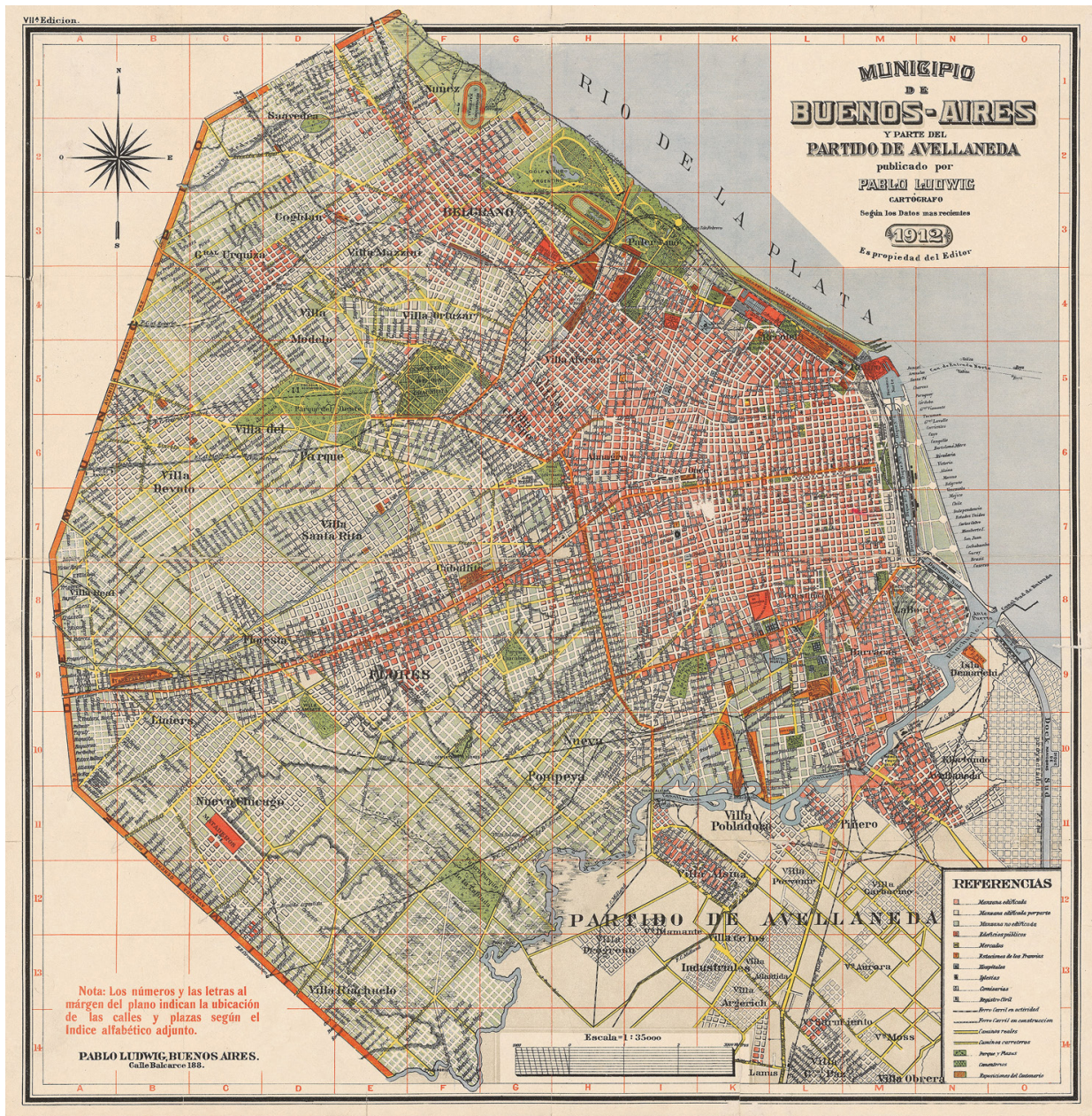

Figura 2. Mapa de la ciudad de Buenos Aires. The University of Chicago Library - Map Collection, 2020.

El territorio de la República Argentina está conformado politicamente por veintitrés provincias y la Ciudad Autónoma de Buenos Aires, Capital Federal a partir de 1880. Esta organización política reconoce sus antecedentes en el largo y complejo proceso histórico de organización del Estado que se desarrolló entre 1810 (independencia) y la sanción de la Constitución Nacional en 1853 (ver Figura1).

La forma del Estado argentino es representativa, republicana y federal con las provincias que se gobiernan y administran dentro de los límites establecidos por la Constitución. Los bienes y territorios de propiedad de la Nación son administrados directamente por el Gobierno central. Como estado federal, la división horizontal de poderes (Poder Ejecutivo, Poder Legislativo, Poder Judicial) combina una división vertical de competencias estatales entre los organismos centrales y las autoridades locales. Motivo por el cual, en determinadas materias, tenemos leyes a nivel nacional y provincial. Las Provincias tienen su propia Constitución, un Gobierno y un Parlamento que garantizan la autonomía y la competencia desde el punto de vista político, administrativo, económico y financiero. Los gobernadores de las provincias son "agentes naturales" del gobierno federal con el objetivo de implementar la Constitución y las leyes de la Nación. A esto se suma la autonomía de la ciudad de Buenos Aires a partir del año 1994 (promulgando su propia constitución en 1996), por lo tanto, se la equipara a una provincia con sus propias leyes. Esto ha producido una doble normativa sobre el patrimonio cultural vigente en el territorio de la ciudad autónoma de Buenos Aires (ver Figura2). 
devenir Vol. 7, N¹4, JULIO- DICIEMBRE 2020, PP. 131-154 - EstUdIOS I ISSN 2312-7562 | E-ISSN 2616-4949 UNIVERSIDAD NACIONAL DE INGENIERÍA, LIMA

doi: https://doi.org/10.21754/devenir.v7i14.974

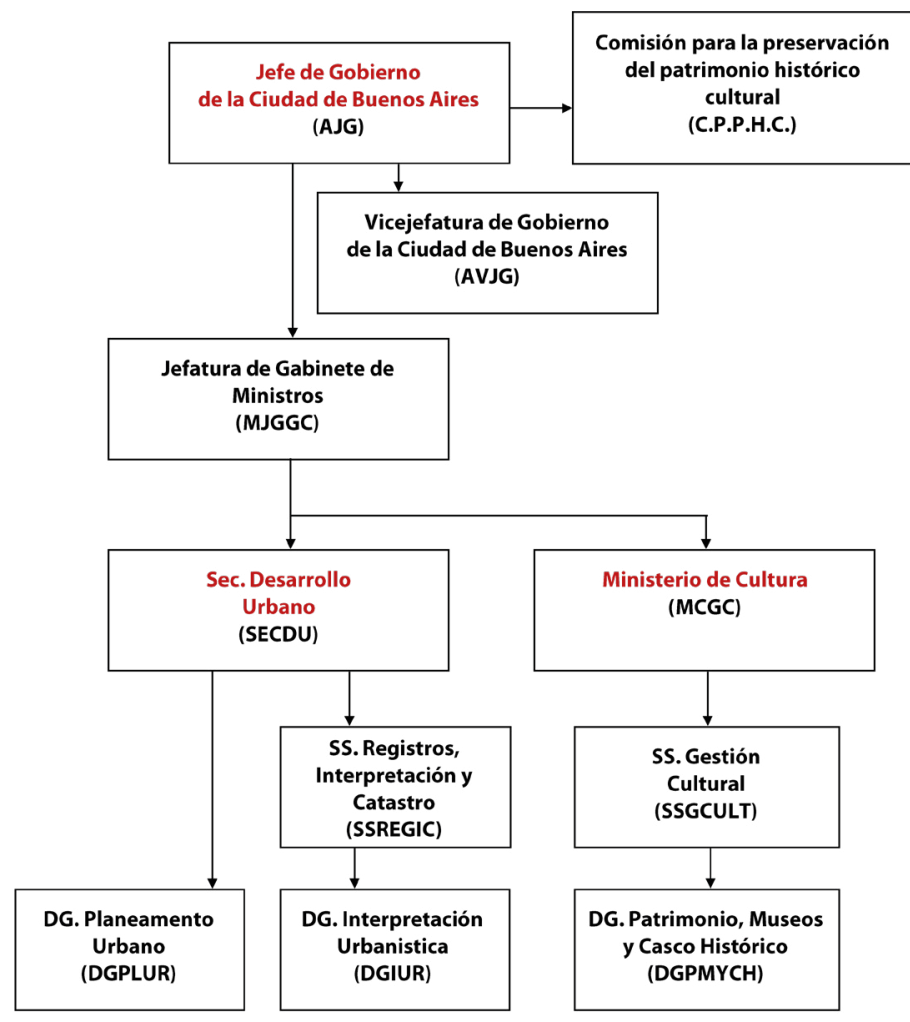

Figura 3. Esquema de la estructura administrativa de los organismos de gobierno que se ocupan del patrimonio de la ciudad de Buenos Aires. Elaboración propia, 2019.

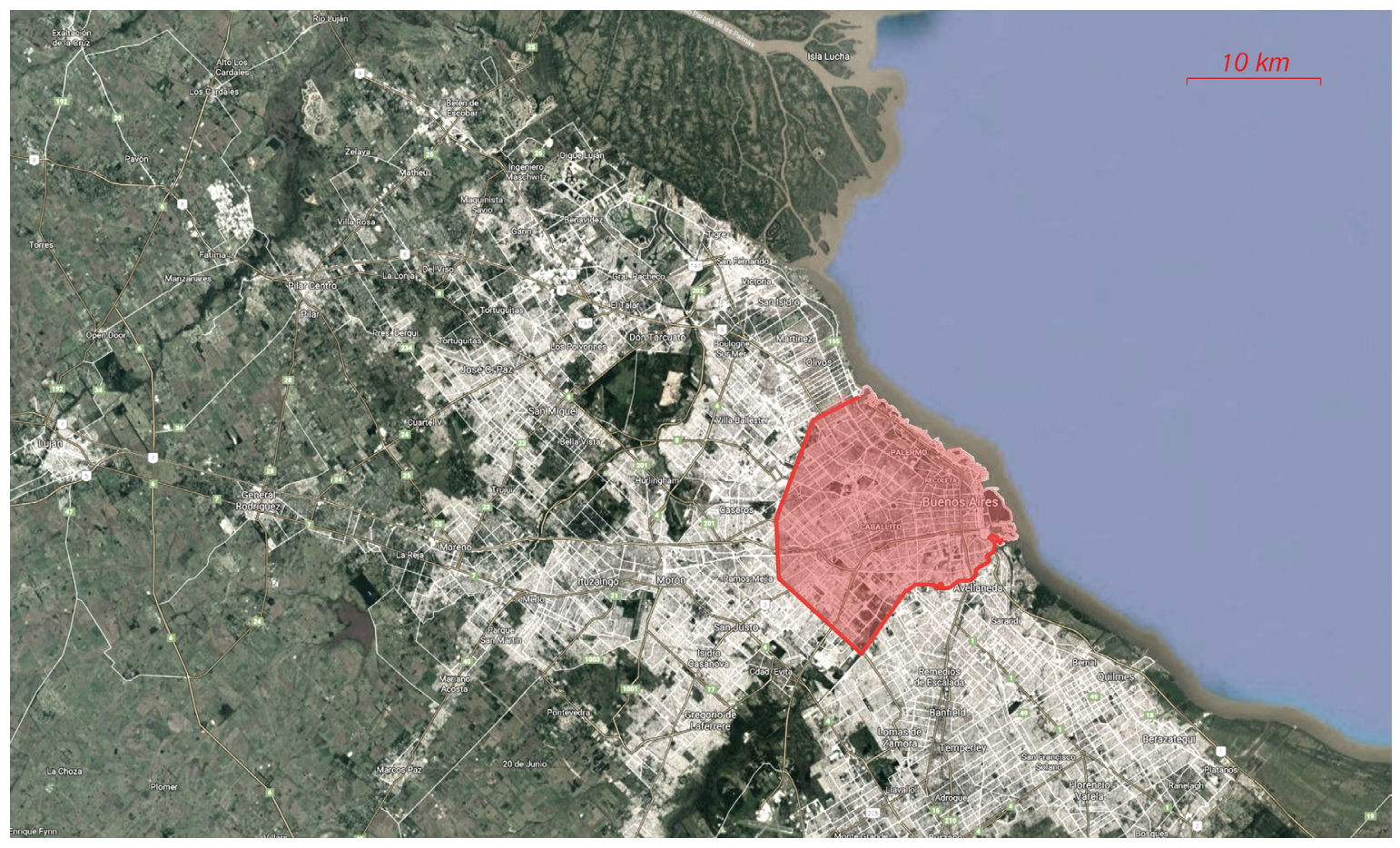

Figura 4. Ciudad Autónoma de Buenos Aires actual (en rojo), con su Área Metropolitana. Elaboración propia, 2020. 


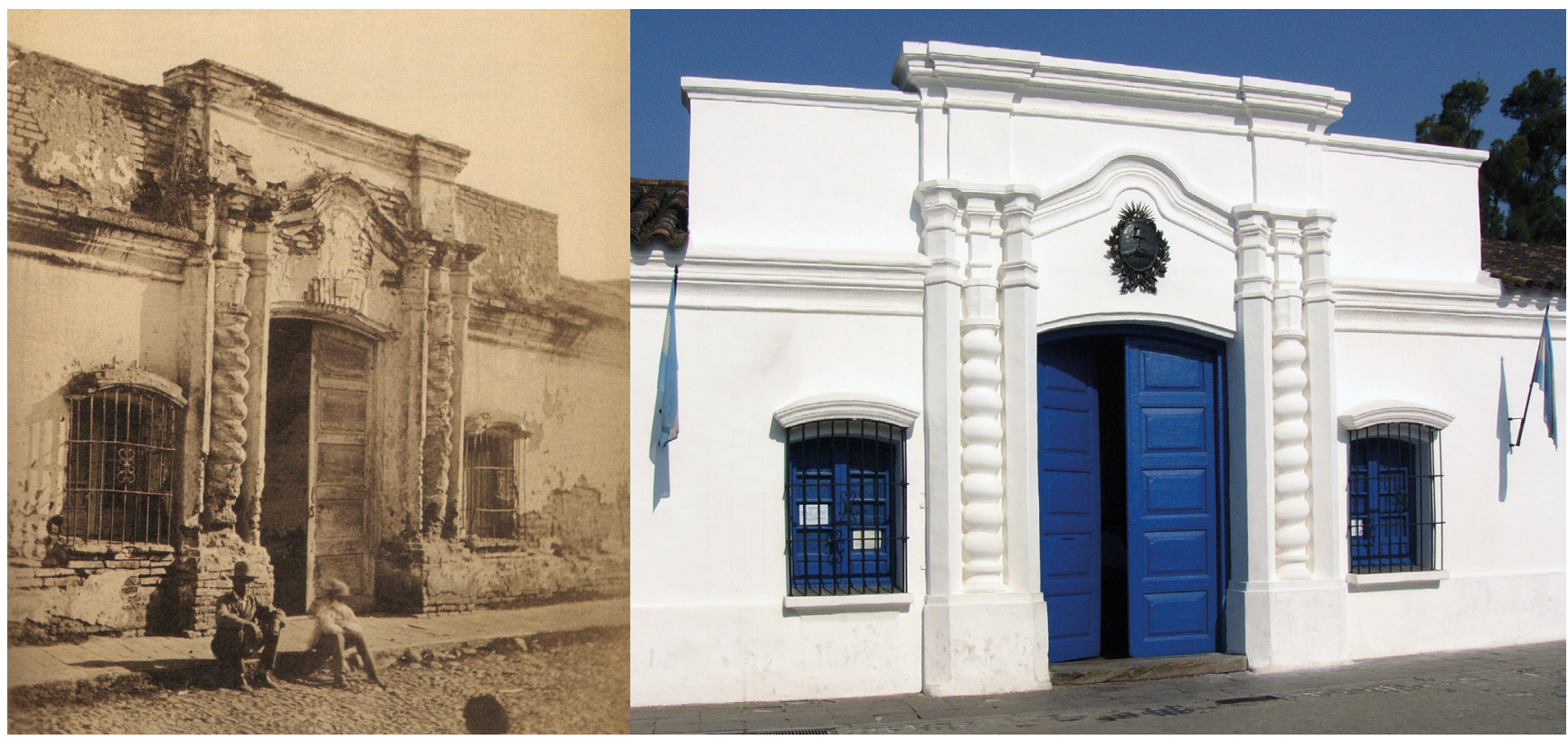

Figura 5. Casa de Tucumán, Argentina. Archivo fotográfico de R. Ferrari (izquierda) y archivo fotográfico de la autora (derecha), 2017.

En Buenos Aires el Poder Ejecutivo es ejercido por el Jefe de Gobierno (asistido por un Gabinete compuesto por ministerios), elegido directamente por los ciudadanos es responsable de administrar la ciudad, planificar su gestión e implementar las normas, además de controlar y supervisar los edificios de utilidad nacional ubicados en la Ciudad (ver Figura 3).

El Poder Legislativo, con un voto de mayoría absoluta, aprueba y modifica los Códigos de Planeamiento Urbano, Ambiental y de Edificación; promulga, a propuesta del Poder Ejecutivo, el Plan Urbano Ambiental de la Ciudad; da nombres a lugares públicos y organiza la disposición de monumentos y esculturas; reconoce y declara monumentos, áreas y lugares históricos de interés público; emite disposiciones reglamentarias sobre la protección y conservación del patrimonio cultural.

En Buenos Aires la presencia del puerto incidió significativamente en la evolución política de la Nación y en la relación entre la ciudad y el territorio. Adquirió un papel preponderante por sus características topográficas, posición geográfica y estratégica frente al Atlántico y al interior del continente, y creó también una dicotomía cultural y social entre la ciudad y el interior del país. Es una ciudad multifacética crecida en el legado del trazado español con la inclusión de elementos provenientes de una población multicultural compuesta principalmente por inmigrantes.

Desde el nacimiento del Estado, la arquitectura y la planificación urbana han jugado un papel eminentemente político en Argentina, pero especialmente en el contexto de la ciudad de Buenos Aires, determinando las estrategias de desarrollo del espacio urbano. Además, la continua alternancia de ideologías discordantes, en cortos períodos de gobierno democrático y en largas dictaduras militares, ha fuertemente influenciado el desarrollo urbano porteño alterando o incluso dañando su tejido (ver Figura 4).

El primer elemento formal de defensa del patrimonio cultural nació por iniciativa del Presidente de la República Domingo Faustino Sarmiento, con ley No. 323 aprobada el 6 de septiembre de 1869. Esta normativa autorizaba al Poder Ejecutivo la compra de la Casa de Tucumán -edificio en el que se proclamó la independencia del país - para protegerla y recuperarla, ya que estaba en un avanzado estado de abandono y degradación (ver Figura 5). 


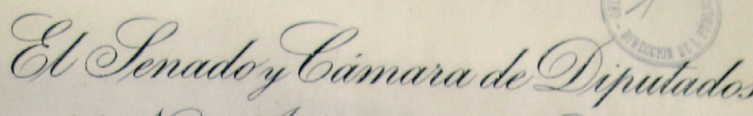

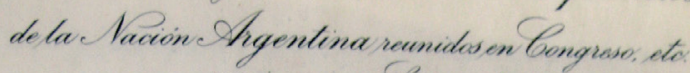

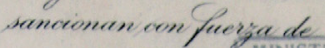

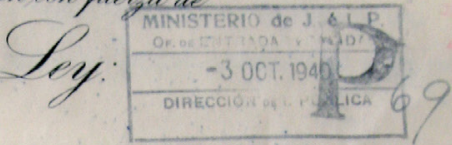

ARTICULO $1^{\circ}$ - Créase la Comisión Nacional de Museos y de Monumentos y Lügares Historicos, dependiente del Ministerio de Justicia e Instrucción Pública, integrada por un presidente y diez vocales, que ejercerån sus funciones con earácter honorario y serán designados por perfodos de seis años, pudiendo ser reelectos.

La comisión tendrá la superintendencia inmediata sobre los museos, monumentos y lugares históricos nacionales y en concurrencia con las respectivas autoridades de las instituciones que se acojan a la presente ley, cuando se trate de museos, monumentos y lugares históricos provinciales o municipales.

ARTICULO $2^{\circ}$.- Los bienes históricos y artísticos, lugares, monumentos, inmuebles propiedad de la Nacion, de las provincias, de las municipalidades o instituciones públicas, quedan sometidos por esta ley a la custodia y conservación del gobier no federal, $y$ en su caso, en concurrencia con las autoridades respectivas.

ARTICULO $3^{\circ}$.- El Poder Ejecutivo a propuesta de la oomisión nacional, declarará de utilidad pública los lugares, monumentos, inmuebles y documentos de propiedad de particulares que se consideren de interés histórico o históricomartistico a los efectos de la expropiación; o se acordará con el respectivo tancice

propietario el modo de asegurar los fines patrí́ticos de esta ley. Si la conservación del lugar o monumento implicase una limitación al dominio, el Poder Bjecutivo indemnizará a su propietario en su caso.

ARTICULO $4^{\circ}$ - La Comision Nacional de Luseos y de Nonumentos y Lugares Históricos, hará la clasificación y formulará la lista. de monumentos históricos del pals, ampliándola en las oportunidades convenientes con la aprobación del Poder Bjecutivo. Los inmuebles hist6ricos no podrán ser sometidos a reparaciones o restauraciones, ni destruidos en todo 0 en parte, transferidos, gravados o enajenados sin aprobación o intervención de la comisión nacional. Bn el caso de que los inmuebles historicos sean de propiedad de las provincias, municipalidades 0 instituciones públicas, la comisión nacional cooperará en los gastos que demande la conservación, reparación o restauracion de los mismos.

ARTICULD $5^{\circ}$.- Ningún objeto mueble o documento historico podrá salir del país, ni ser vendido ni gravado sin dar interven eión a la comisión nacionel, y ésta hará las gestiones para su adquisicion cuando sea de propiedad de particulares y considere convenientes tales gestiones por razones de interés público.

ARTICULO $6^{\circ}$ - L Los inmuebles comprendidos en la lista y clasificación oficial de la comisión nacional estarán libres de toda earga impositive.

ARTICULO $7^{\circ}$ - - La comisión nacional está facultada para acep-
Figura 6. Ley $\mathrm{N}^{\circ} 12.665$ del 3 de octubre 1940: Creación de la Comisión Nacional de Museos y de Monumentos yLugares Históricos Archivo General de la Nación Argentina, Fondo Ministerio de Justicia e Instrucción Pública, Decretos Originales, octubre 1940, Legajo 121, 2018

\section{Nivel nacional}

A nivel Nacional (Argentina) la ley sobre la protección arqueológica de 1913 (No. 9.080) inauguró el procedimiento legislativo en materia de bienes culturales, mientras los países europeos ya estaban dictando leyes de reforma y Francia había modificado la propia. Son muchas las razones que explican este retraso, entre ellas las guerras por la independencia, las luchas civiles del siglo XIX y, sobre todo, el escaso patrimonio histórico existente, como así también la falta de un clima culturalmente adecuado. En efecto, el sentimiento de búsqueda de los propios orígenes nació cuando el País comenzó a tener una cierta apariencia de estabilidad política y también fue consecuencia de los debates originados con las celebraciones del centenario de la independencia. ${ }^{1}$

La ley sobre la protección de los bienes culturales tomó forma en 1937 (decreto No. 118.588) con la institución de la primera estructura burocrática estatal: la "Superintendencia de Museos y Lugares Históricos", dependiente del Ministerio de Justicia e Instrucción Pública. Esto se produjo tras una amplia serie de demoliciones, consecuencia de los trabajos realizados para las celebraciones de la independencia de la Nación

\footnotetext{
1. A finales del siglo XIX, coincidiendo con la prosperidad económica del país, surgen fenómenos de'vandalismo' fomentados por las mismas autoridades. El objetivo fue renovar y modernizar los edificios con motivo del primer centenario de la independencia de la República Argentina (que ocurrió en 1810), por lo tanto, se trató de una serie de demoliciones que se dieron en todo el país y causaron grandes daños al destruir varios edificios antiguos públicos y privados.
} 


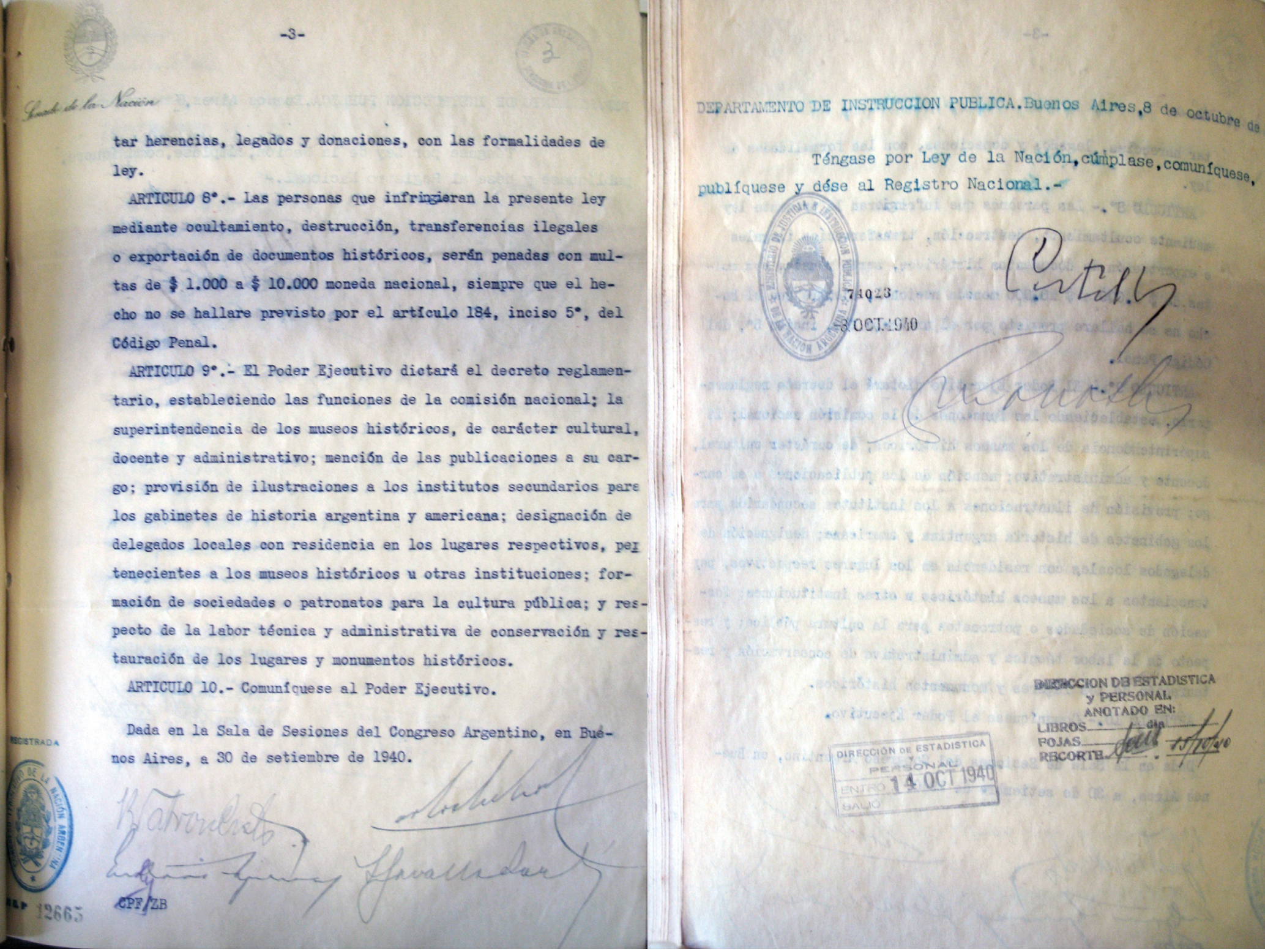

(1910), que hizo nacer una primera voluntad de conservar los edificios representativos. Se demolieron edificios municipales provinciales antiguos para reemplazarlos por lujosas Casas de Gobierno. Desaparecieron en silencio varios Cabildos (entre ellos el de Humahuaca -Jujuy-, Santa Fe, Santiago del Estero, Corrientes y Tucumán) y en Buenos Aires se abatieron el antiguo Fuerte, la Aduana española, la Vieja Recova, el Real Colegio de San Carlos y la Casa de la Virreina, mientras que los templos bonaerenses antiguos se modernizaron según el gusto predominante de principios del siglo XX (Buschiazzo, 1959).

Al año siguiente la Superintendencia se transformó en Comisión Nacional con la tarea de elaborar un verdadero proyecto de ley para su organización. En 1940, basándose en el aporte de la legislación extranjera, en especial la francesa, se aprobó y promulgó la primera ley relativa a la conservación del patrimonio histórico y artístico de la Nación: la "Ley Nacional sobre Museos, Monumentos y Lugares Históricos. Comisión nacional de museos monumentos y lugares históricos. Defensa del patrimonio histórico y artístico de la Nación", No. 12.665 (ver Figura 6).

Esta ley, si bien se amplió y modificó en algunas partes, aún está vigente hoy.²

2. En 1993 se promulgó la ley 24.252 que reformó la ley $12.665 / 40$ con el objetivo de fortalecer las funciones de la Comisión Nacional dando más peso a sus decisiones y asignándole el papel de órgano consultivo del Congreso Nacional en materia de patrimonio cultural. 
La Comisión Nacional (CNMMyLH) ${ }^{3}$ posee funciones variadas, como la superintendencia de los bienes protegidos en concurrencia con autoridades locales cuando correspondiere, la de intervenir como consultora en las labores de mantenimiento o de reestructuración de los inmuebles de valor histórico, autorizar las intervenciones de demolición parcial o total; controlar las obras de reestructuración en los lugares protegidos; definir y precisar el régimen jurídico de los bienes privados objeto de protección. ${ }^{4}$ Además redacta y gestiona el 'Registro Nacional de Bienes Históricos e Histórico Artísticos' (estableciendo criterios de selección de estos bienes), estructurado en: bienes de interés histórico (sepulcro histórico; ciudad, barrio o centro histórico; paisaje urbano y natural); monumento histórico nacional; lugar histórico nacional (sitio histórico, sitio arqueológico, pueblo histórico). La inscripción de un objeto de importancia nacional significa que éste merece ser preservado de modo particular o, en la medida de lo posible, salvaguardado. Para su redacción se requiere la ayuda de cada provincia para identificar los edificios a proteger dentro de su territorio. ${ }^{5}$ Este registro/inventario no es definitivo, y se actualiza constantemente. La lista de los Monumentos y de los Lugares Históricos Nacionales todavía es muy pobre (actualmente hay 4.500 bienes registrados) y la defensa de los edificios se orienta principalmente a eventos históricos y no formales. Esto no se debe a las limitaciones de la legislación vigente, sino a la discrecionalidad (entendida como sensibilidad o cultura sobre el tema) de los miembros que integran la CNMMYLH.

En 1949, durante la presidencia de Domingo Perón, la reforma de la Constitución definió al Estado argentino como un "Estado de cultura" con la tarea de tutelar el patrimonio histórico, artístico y paisajístico. La nueva constitución, que modificó la original de 1853 , considera la cultura como una de las responsabilidades fundamentales del Estado. De hecho, en el capítulo III, 37 , IV, párrafo $7^{\circ}$ se afirma que:

Las riquezas artísticas e históricas, así como el paisaje natural, cualquiera sea su propietario, forman parte del patrimonio cultural de la Nación y estarán bajo la tutela del Estado, que puede decretar las expropiaciones necesarias para su defensa y prohibir la exportación o enajenación de los tesoros artísticos. El Estado organizará un registro de la riqueza artística e histórica que asegure su custodia y atienda a su conservación.

En 1956, el gobierno militar, restableciendo la Constitución de 1853, eliminó las disposiciones relativas a la cultura, reintroducidas nuevamente por el gobierno de Carlos Menem en la década de 1990 en el momento de la modificación de la constitución.

A partir de la última breve presidencia de Perón (1973) y hasta el advenimiento de la democracia (1983), la estructura administrativa dedicada a la tutela del patrimonio cultural nacional sufrió continuas reorganizaciones entre el Ministerio de Educación y el área presidencial.

En 1982 se emitió el decreto 1.063, sobre la defensa de los bienes inmuebles de cualquier naturaleza jurídica, que tengan una antigüedad de más de 50 años y que sean propiedad del Estado o de entidades descentralizadas o de empresas y sociedades del Estado. Para cualquier intervención y/o modificación se deberá solicitar la opinión de la CNMMYLH que evaluará la conveniencia o no de las medidas que se intentan, teniendo en cuenta el valor histórico, artístico y arquitectónico del edificio. En 1991, con el

\footnotetext{
3. n 2015 la ley 27.103 modificó la norma 12.665 trasformando a la Comisión en "Comisión Nacional de Monumentos, Bienes y Lugares Históricos".

4. Decreto n. 84.005/41 Reglamento de la Comisión Nacional aprobado por el P.E., Buenos Aires, 7 de febrero 1941.

5. Desde el año de creación del CNMMYLH comenzó la publicación anual de la actualización de la lista de edificios monumentales. La lista está dividida por provincia y organizada en orden alfabético. Para cada edificio, acompañado de una foto de detalle, se indica la ubicación, la descripción histórica y actual.
} 
Decreto n. 1.392, se aprobó una nueva estructura orgánica del Ministerio de Cultura y Educación y de la Subsecretaría de Cultura de la Nación. En el mismo año, la CNMMYLH (Disposición 6/91) examinó nuevamente el concepto de patrimonio cultural considerando también el tiempo histórico, la escala espacial y el campo social. También introdujo el 'paisaje' (tanto urbano como natural) como un nuevo tipo de bien cultural, por lo tanto, ya no solo el monumento aislado, sino también su entorno inmediato.

A nivel nacional, además de la ley 12.665/1940, se introduce el concepto de tutela y conservación del patrimonio natural y cultural en la modificación de la Constitución efectuada en 1994 y se incluyen los delitos contra la propiedad en el Código Penal con un agravante si se trata de un bien cultural. El Estado asume la obligación de generar las leyes de protección de los bienes de acuerdo con lo establecido en la Constitución Nacional (art. 41) y fijará los elementos mínimos de protección a través de leyes marco que las provincias integrarán y aplicarán. De esta forma se reconoce el carácter participativo de la Nación y de las provincias en la función de protección del patrimonio cultural. Además, el Estado se ocupará de coordinar una administración que ponga en práctica las políticas generadas por los dictámenes de la nueva legislación. Dicha organización operará de manera coordinada con los organismos provinciales, los cuales tendrán la responsabilidad de cumplir las reformas necesarias tanto desde el punto de vista legal como administrativo para adecuarse a los nuevos requerimientos. Tras el nuevo estatuto de ciudad autónoma asignado a Buenos Aires en 1994, la ley 24.588/95 establece que permanecerán bajo la jurisdicción federal todos los inmuebles ubicados en la ciudad de Buenos Aires que sean sede de los poderes de la Nación, así como cualquier otro bien de propiedad de la Nación.

En 1999 fue sancionada la ley 25.197 para la reglamentación del registro del patrimonio cultural con el objeto de centralizar los datos de los bienes culturales de la Nación que a partir de la identificación y registro del mismo será denominado "Registro Nacional de Bienes Culturales". Esta norma define como bienes culturales a "todos aquello objetos, seres o sitios que constituyen la expresión o el testimonio de la creación humana y la evolución de la naturaleza y que tienen un valor arqueológico, histórico, artístico, científico o técnico excepcional." La autoridad de aplicación de esta ley es la Secretaría de Cultura de la Nación, la cual tiene que coordinar con los gobiernos provinciales y con el Gobierno de la Ciudad de Buenos Aires la implementación de una red de registros comunes. ${ }^{6}$

En 2003 fue promulgada la ley 25.743 sobre la preservación, protección y tutela del Patrimonio Arqueológico y Paleontológico en todo el territorio argentino como parte integrante del Patrimonio Cultural de la Nación. ${ }^{7}$ Esta ley establece directivas con respecto al dominio sobre los bienes arqueológicos y paleontológicos, confiriendo a las provincias y al Gobierno Autónomo de Buenos Aires la facultad exclusiva de organizar en sus respectivas jurisdicciones un registro Nacional de sitios arqueológicos y paleontológicos; un registro Nacional de yacimientos, colecciones y objetos arqueológicos o restos paleontológicos; autorizar la realización de investigaciones en áreas arqueológicas y paleontológicas; aplicar infracciones y sanciones penales por violaciones de la ley; brindar protección especial cuando se trate de materiales de tipo paleontológico, etc.

\footnotetext{
6. Entre las diferentes funciones, la Secretaría de Cultura de la Nación (hoy Ministerio de Cultura) debe: realizar el relevamiento de los bienes culturales pertenecientes a la Nación; catalogar los bienes culturales presentes en entidades que no tienen esa tarea; identificar los bienes culturales que forman parte del registro único; crear una base de datos con imágenes del patrimonio cultural de la Nación; desempeñar el papel de superintendencia sobre el conjunto de bienes que forman parte del patrimonio histórico y cultural de la nación.

7. El organismo nacional encargado de la aplicación de esta ley sobre el patrimonio arqueológico es el Instituto Nacional de Antropología y Pensamiento Latinoamericano dependiente de la Secretaría de Cultura de la Nación, mientras que el Museo Argentino de Ciencias Naturales Bernardino Rivadavia dependiente de la Secretaría de Ciencia, Tecnologia e Innovación Productiva del Ministerio de Educación, Ciencia y Tecnologia de la Nación se ocupa del patrimonio paleontológico.
} 


\section{Nivel provincial}

A nivel provincial se han promovido y desarrollado diversas leyes que protegen el patrimonio cultural que, a pesar de las dificultades técnicas y prácticas en su implementación, determinan las obligaciones en el ámbito de la conservación del patrimonio cultural. A título informativo, para la provincia de Buenos Aires pueden citarse la ley 8.912/77 "Ley de ordenamiento territorial y uso del suelo" que entre sus objetivos fundamentales establece el ordenamiento del territorio, la conservación de las áreas y lugares de interés natural, paisajístico, histórico o turístico. Sucesivamente la ley 10.419/86 que establece la creación de la Comisión Provincial del Patrimonio Cultural de la Provincia de Buenos Aires dependiente de la Dirección General de Escuelas y Cultura, con el objetivo de planificar y controlar las políticas de conservación y tutela de los inmuebles declarados bienes culturales de forma provisional o definitiva. Entre las tareas de la Comisión encontramos también el relevamiento, el registro, el inventario y la valorización de los bienes, así como también la promulgación de normativas sobre el tema.

\section{Ciudad Autónoma de Buenos Aires}

Según lo decretado por la modificación de la Constitución Nacional de 1994, en 1996 la ciudad de Buenos Aires se convirtió en autónoma. Se aprueba y publica una Constitución propia en la que algunos artículos están dedicados a los aspectos de la tutela y preservación del patrimonio cultural.

El art. 27 pone en cabeza del Estado local la política de gestión y planeamiento urbano integrada a las políticas de desarrollo económico, social y cultural que contemple su inserción en el área metropolitana. El objetivo es promover la preservación y restauración del patrimonio arquitectónico y urbanístico; proteger e incrementar los espacios públicos y recuperar las zonas costeras. El art. 32 expresa claramente su intención de operar en el ámbito de la tutela de los propios bienes garantizando "[...] la preservación, recuperación y difusión del patrimonio cultural, cualquiera sea su régimen jurídico y titularidad, la memoria y la historia de la Ciudad y sus barrios.." En cuanto a la protección, el art. 29 y 104 inc. 22, establecen la creación de un Plan Urbano Ambiental que se fundamenta en el "[...] concepto de desarrollo sostenible, concebido como un proceso participativo, que integra la transformación urbanística, el crecimiento económico, la igualdad social, la protección de la diversidad cultural y el uso racional de los recursos ambientales [...]". Además, el art. 137 crea la figura de la "Defensoría del Pueblo", órgano independiente que desempeña su rol en completa autonomía funcional y financiera. Su objetivo es la defensa, protección y promoción de los derechos humanos y demás derechos e intereses individuales, colectivos y difusos tutelados por el art. 41 de la Constitución Nacional, el art. 32 de la Constitución de la CABA y otras leyes.

Además, el art. 81 confiere a la Legislatura el poder de introducir modificaciones al Código de Planificación Urbana, Ambiental y de Edificación, de declarar nuevos monumentos, áreas y sitios históricos y de legislar en materia de preservación y conservación del patrimonio cultural.

En resumen, los objetivos de la Constitución en cuanto a los aspectos del patrimonio son: la transformación de la estructura urbana centralizada existente en una estructura policéntrica reforzada con entidades barriales; expansión y mejora de los espacios verdes, de las vías públicas y de las áreas de calidad ambiental; creación de nuevas herramientas de gestión urbano/ambiental tanto a nivel inter-jurisdiccional como local; reconocimiento de las diferentes áreas de protección (APH).

Los instrumentos legislativos para implementar los objetivos de la Constitución se formalizaron en el Código de Planificación Urbana del año 2000 -sección 10- (a través de la 'Dirección General de Interpretación Urbanística' del Ministerio de Desa- 
rrollo Urbano actúa sobre los bienes culturales arquitectónicos en lo que hace a las políticas de desarrollo y gestión territorial) y en la ley marco 1.227/2003 a través de la 'Subsecretaría de Patrimonio Cultural' del Ministerio de Cultura en cuanto a las políticas de protección, conservación y restauración del patrimonio arquitectónico, natural y urbanístico. ${ }^{8}$

\section{Antecedentes históricos}

En el tejido urbano comienza un proceso de densificación como consecuencia de la Ley 13.512 de Propiedad Horizontal de 1948, que permitía la propiedad individual dentro de un único edificio, hasta entonces prohibida por el Código Civil, y con la introducción del edificio en "torre" en 1957.

En Buenos Aires el patrimonio arquitectónico comenzó a ser objeto de debate hacia fines de los años 60, luego de intervenciones de recuperación en marcha en los barrios del centro histórico (casas antiguas de San Telmo y Monserrat). Intervenciones, públicas y/o privadas, desarrolladas en una época en la cual la tendencia predominante era el "desprecio por la herencia arquitectónica", calificada como "vieja": se conservaban solo los edificios "monumentales", y los que los rodeaban debían cambiar en nombre del progreso. Se negaban las características del lugar promoviendo la construcción de edificios que contrastaban con la historia y la identidad locales, con frecuencia fuera de escala en relación al entorno inmediato, realizados gracias a las modificaciones de leyes introducidas.

El Código de Planificación de 1977, reforzando el concepto de centro de manzana libre, favorecía la construcción en altura. Esta situación provocó daños relevantes al patrimonio arquitectónico más representativo del país, y también intervenciones abusivas de demolición y/o reestructuración con frecuencia especulativas (ver Figura 7).

Éste es el debate histórico-cultural que acompañó el nacimiento, en 1992, de la normativa No. 45.517, que introduce un concepto muy importante, el de las "Áreas de Protección Histórica" (APH), que en 1994 se extendió a sitios de interés cultural ${ }^{9}$ (ver Figura 8).

En el año 2000 se promulgó el nuevo Código de Planificación Urbana, ley 449, con la sección 10 dedicada totalmente a la protección de los bienes culturales; además, en la sección 5 "zonificación en distritos", se retoman y amplían los Distritos Áreas de Protección Histórica (APH), es decir, áreas, espacios o complejos urbanos que por su valor (histórico, arquitectónico, individual y ambiental), son herencia de la cultura argentina. A estas áreas se atribuye una protección especial tanto a "nivel edificio" como a "nivel ambiental".

Los niveles de protección relativos a los edificios son: protección total (salvaguarda la totalidad del edificio conservando todas sus características arquitectónicas y sus formas de ocupación del espacio. Se permiten trabajos de consolidación y mantenimiento, pero no un cambio en el volumen o la superficie construida); protección estructural (tutela la parte externa del edificio, la tipología y todos los elementos fundamentales que determinan su forma y ocupación del espacio, permitiendo al mismo tiempo aportar cambios que no alteren el volumen. Permite la adaptación del espacio interno

\footnotetext{
8. El Ministerio de Cultura se dedica al patrimonio cultural en todas sus formas, tangibles e intangibles, mientras que el Ministerio de Desarrollo Urbano está vinculado al patrimonio arquitectónico y urbanístico.

9. Las APH son una especie de ZPPAUP (zonas de protección del patrimonio arquitectónico, urbano y paisajístico) francesas, que representan una carta ganadora para el desarrollo de toda la ciudad en cuanto elemento fuerte de identificación colectiva y recurso para un correcto uso turístico.

En el ordenamiento de las APH se subraya la necesidad de crear un catálogo, pensado como una nueva herramienta de control urbanístico.
} 
devenir Vol. 7, N¹4, JULIO-DICIEMBRE 2020, PP. 131-154 - EstudIOS I ISSN 2312-7562 I E-ISSN 2616-4949

UNIVERSIDAD NACIONAL DE INGENIERÍ, LIMA

doi: https://doi.org/10.21754/devenir.v7i14.974

Figura 7. Buenos Aires, Argentina, ejemplos del proceso de densificación con torres que contrastan con los edificios. Archivo fotográfico de la autora, 2019.

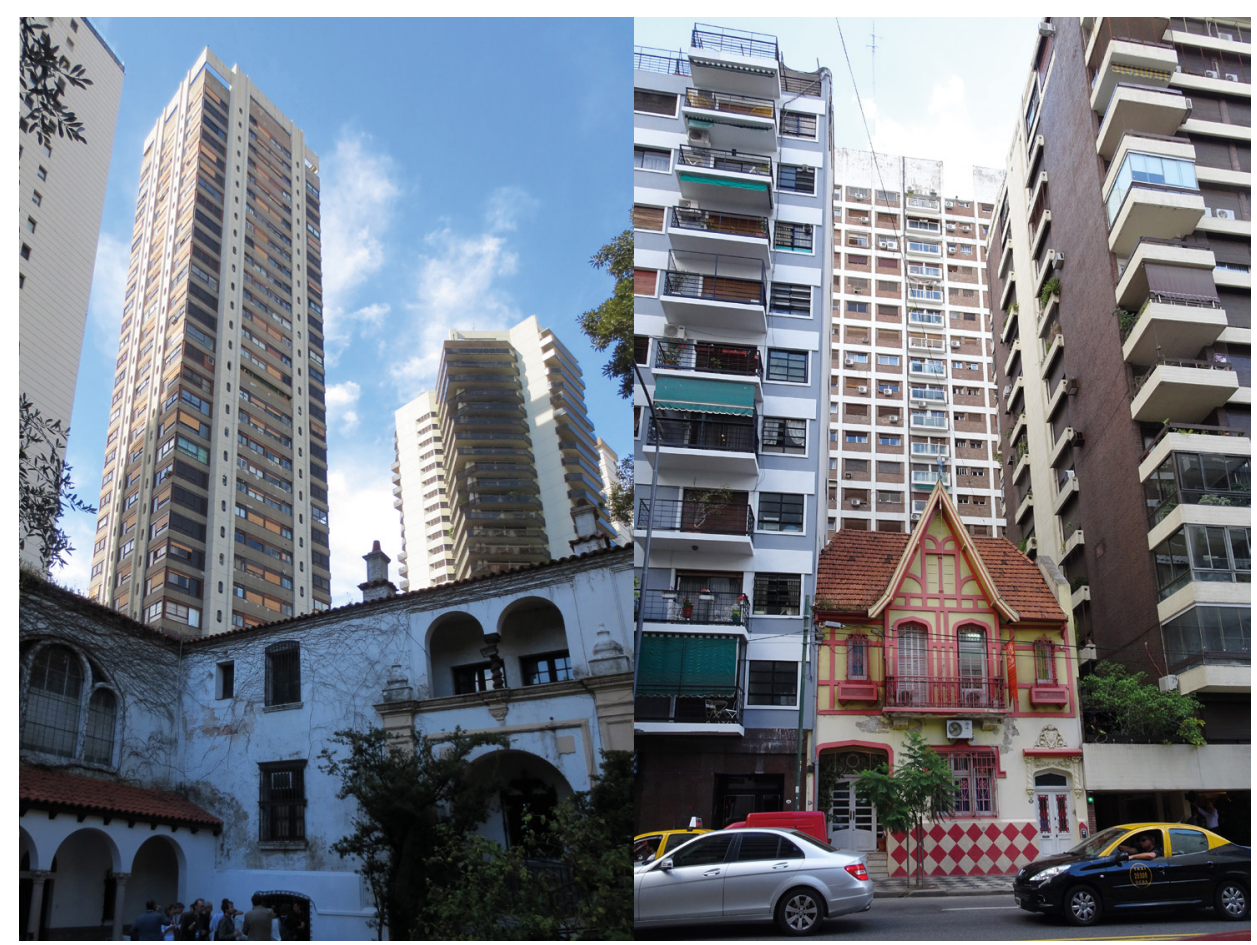

del edificio para afectarlo a nuevos usos respetando los elementos tipológicos, formales y estructurales); protección cautelar (protege la imagen característica del área, tratando de evitar intervenciones en contraste con el tejido y la morfología urbana).

La protección a nivel ambiental (espacio público) también tiene tres niveles: 1. ambientes consolidados; 2 . ambientes preconsolidados; 3 . ambientes potenciales, en función del grado de homogeneidad espacial, de la presencia en cantidad y calidad de edificios de valor histórico y de las condiciones espaciales y funcionales para su uso. En modo particular, espacios públicos con situaciones espaciales interesantes (proporciones, trama, escala, vistas) y con elementos arquitectónicos significativos. Se incluyen asimismo los espacios que, por su ubicación estratégica, pueden relacionar otros fragmentos del tejido urbano.

En 2003 se promulgó la "Ley marco de Patrimonio Cultural de la Ciudad Autónoma de Buenos Aires" n. 1.227/2003 (reglamentada en el 2005) la cual establece el marco legal para la investigación, conservación, restauración y salvaguardia del patrimonio cultural. La Resolución 1.371/06 del Ministerio de Cultura designó la Subsecretaría de Patrimonio Cultural como ente ejecutor. Esta ley explicita la necesidad de una labor de protección de los bienes culturales que sea abarcadora e integral. Hasta este momento había prevalecido una visión puntual de la conservación, separada entre el carácter "natural" y el "cultural", con una gestión a cargo de áreas administrativas separadas, con poco diálogo entre ellas, y con criterios diferentes. Establece, además, que los bienes que pertenecen al patrimonio cultural no se pueden ceder, transferir, modificar o destruir sin la intervención del ente de aplicación. El ente consultor permanente es la "Comisión para la Preservación del Patrimonio Histórico Cultural de la Ciudad de Buenos Aires".

Además, para implementar lo que exige la ley nacional 25.197/99, se crea la Unidad Técnica de Coordinación Integral de Catálogos, Registros e Inventarios (UTCICRI) para recopilar y coordinar de manera completa toda la información existente sobre el patrimonio cultural de la Ciudad, proveniente de cualquier fuente, perteneciente tanto 


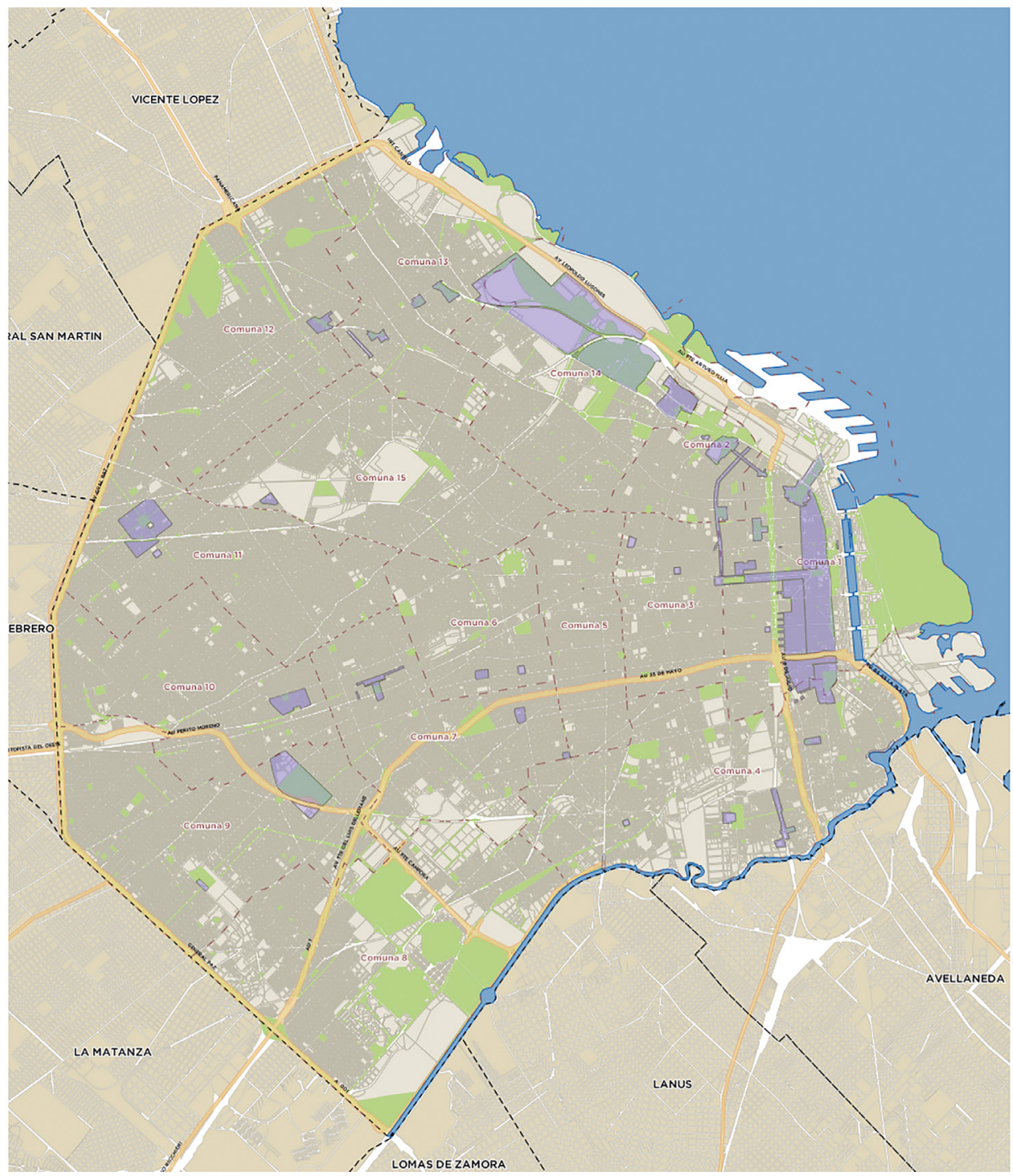

Figura 8. Plano actual de la Ciudad de Buenos Aires con las Áreas de Protección Histórica. Gobierno de la ciudad de Buenos Aires, 2020.

al sector público como privado para concluir en un registro único y completo de los bienes catalogados o en proceso de catalogación.

\section{Inventario y catálogo}

Tras algunas iniciativas de los años ' 80 , que dieron lugar a publicaciones, y que podríamos definir mejor como censo científico ${ }^{10}$, y a la guía de arquitectura de Buenos Aires (proyecto de investigación realizado en colaboración entre el gobierno de la ciudad de Buenos Aires y la Consejería de Obras Públicas y transportes de Sevilla, que quería mostrar la ciudad a través de ocho recorridos correspondientes a las diferentes y

10. El primero fue el "IPU Inventario de Patrimonio Urbano" que preveía el inventario de cada uno de los barrios de Buenos Aires, pero solo se pudieron completar unas pocas áreas. Se trató de un proyecto de investigación de la Secretaría de Investigación y Posgrado de la Facultad de Arquitectura y Urbanismo de la UBA con el patrocinio de la CNMMYLH y de la Subsecretaría de Cultura del Ministerio de Educación y Justicia. 


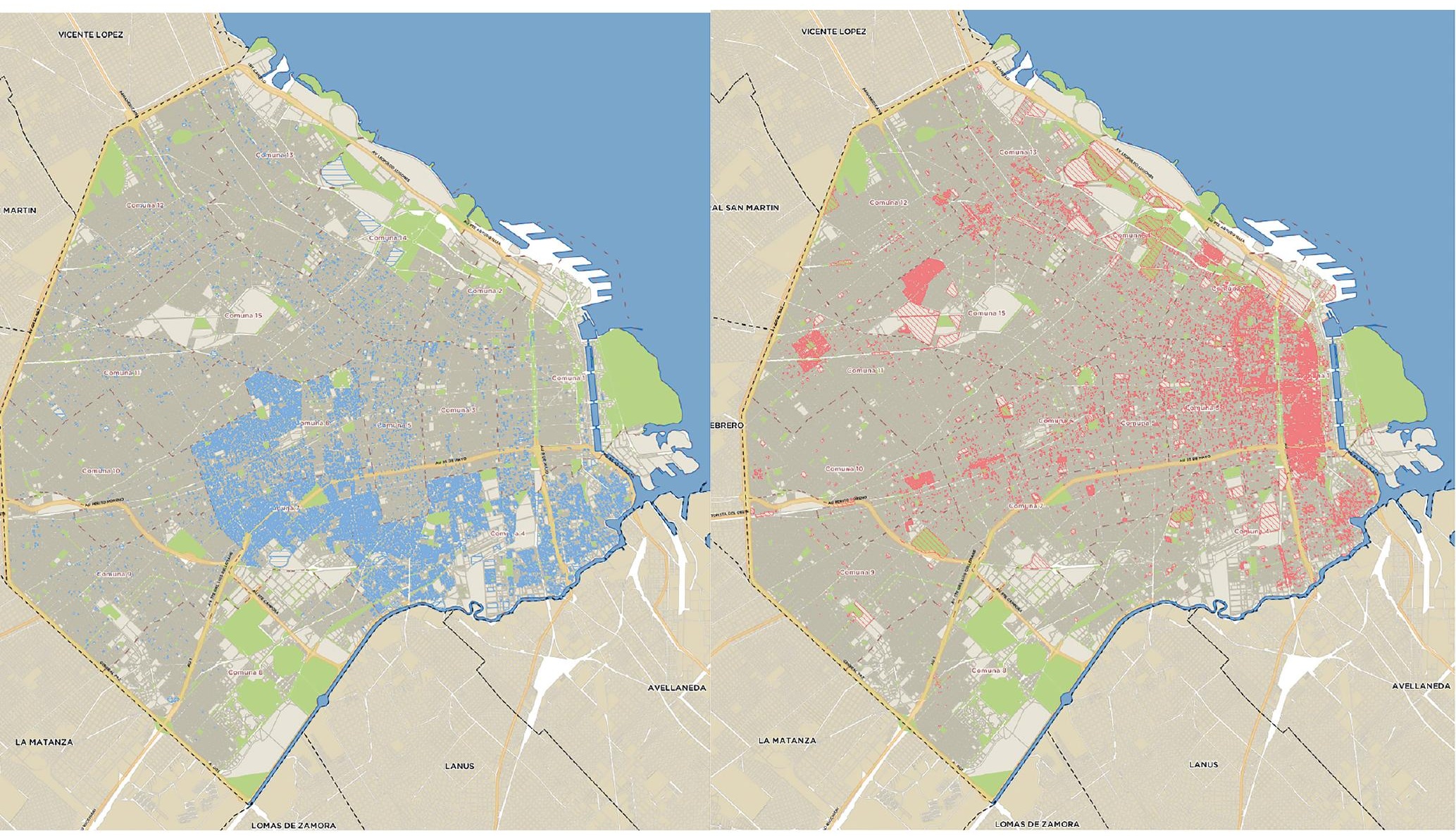

Figura 9. Mapa de la Ciudad Autónoma de Buenos Aires con evidenciados en azul los edificios construidos antes del 31 de diciembre de 1941 sin catalogar. Gobierno de la ciudad de Buenos Aires, 2020

Figura 10. Mapa de la Ciudad Autónoma de Buenos Aires con evidenciados en rojo los edificios catalogados. Gobierno de la ciudad de Buenos Aires, 2020. más importantes áreas) ${ }^{11}$, la Dirección General de Patrimonio e Instituto Histórico del Ministerio de Cultura comenzó a elaborar el inventario a partir de un amplio elenco de edificios de valor histórico-arquitectónico-cultural compuesto por: edificios representativos; edificios Premio Municipal de Fachada y alrededor de 9.000 bienes del proyecto 'Buenos Aires Paisaje Cultural' (para proponer la ciudad como patrimonio mundial de la Unesco), concluyendo con la publicación de una serie de volúmenes: Guías del Patrimonio Cultural de Buenos Aires. Estas guías ofrecen una visión general de los bienes inmuebles, los lugares y los paisajes de la ciudad examinando edificios de arquitectura moderna, industrial, neocolonial y art decó. Estas publicaciones no fueron pensadas exclusivamente para visitantes extranjeros, sino que también están dirigidas a un público más amplio, los porteños y los argentinos en general, con el objetivo de que todos conozcan el patrimonio arquitectónico de la ciudad. ${ }^{12}$ Como pide la ley
11. Cada recorrido inicia con un texto que encuadra el carácter general del área en cuestión, intentando trazar significativamente un perfil principalmente histórico-arquitectónico, una planta con la indicación de los puntos a visitar seguido de una única ficha descriptiva con la relativa documentación gráfica y fotográfica. Los criterios de relevamiento y la metodología de investigación están en relación con las características tipológicas de los edificios.

12. Cada ficha contiene la información necesaria para dar a conocer la importancia histórica y artística de la obra, los autores, la función y las condiciones jurídicas de cada edificio. El criterio de selección de los edificios se basa en el valor cultural, turístico e histórico y en aquellos declarados protegidos por el Estado Nacional o por el Gobierno de la ciudad de Buenos Aires. La lista se divide según la tipología arquitectónica: civil, industrial y religiosa. 
1.227/2003, el Ministerio de Cultura creó 'Acceder', un catálogo digital del patrimonio arquitectónico de la ciudad.

Según lo solicitado por la sección 10 del Código de Planificación, se introduce asimismo otro instrumento que contribuye a la acción de tutela que es el "Catálogo de los inmuebles de valor cultural" de la ciudad de Buenos Aires, ubicados o no en las APH, redactado y constantemente actualizado por la Secretaría de Planeamiento. Los inmuebles aquí incluidos estarán sujetos a los grados de protección edilicia descritos en precedencia. La catalogación se efectúa según el "valor urbanístico" (concerniente a las cualidades del edificio que definen o califican el paisaje urbano o el espacio público); el "valor arquitectónico" (referido a elementos de calidad estilística, compositiva, material y coherencia tipológica, etc.); el "valor histórico-cultural" (elementos que testimonian una organización social o forma de vida representativa de la memoria histórica colectiva y un uso social actual); y el "valor singular" (características peculiares en lo que hace a los aspectos técnicos constructivos, el diseño del edificio o el lugar). Los criterios de valorización deben considerarse en función de los elementos a proteger, del análisis del contexto urbano y de los objetivos de planificación del área.

Según lo establece el Código de Planeamiento Urbano del 2000, la Supervisión Patrimonio Urbano de la Dirección General de Interpretación Urbanística de la Secretaría de Planeamiento del Ministerio de Desarrollo Urbano comenzó a realizar el inventario de los edificios que merecen protección, por cada barrio, asignando a cada uno de ellos un grado de resguardo que establece cuáles intervenciones se admiten. Un trabajo que se aproxima a un catálogo con la descripción de los datos más significativos del objeto ${ }^{13}$, que tuvo como resultado la publicación "Atlas de edificios catalogados". La Ciudad cuenta en la actualidad con 16.000 inmuebles con un grado de protección específica, más de 140.000 edificios reseñados con la ley $2.548 / 2007$, luego reemplazada por la ley 3.056 del año 2009, que confería protección a los inmuebles que fuesen representativos del patrimonio cultural de la ciudad o construidos antes del 31 de diciembre de 1941 (se estima que en la Ciudad hay alrededor de 134.000 inmuebles anteriores a esta fecha). Ley que, a pesar de tener un propósito positivo, ha generado efectos adversos al promover entre los propietarios la demolición preventiva (antes de la entrada en vigor de la ley) de edificios de baja altura sujetos a limitaciones, como la mayoría de los petit hotel y casas de renta para garantizar el reemplazo por edificios de mayor altura (ver Figuras 9, 10 y 11).

El plazo de la ley 3.056 fue prorrogado hasta 2011. Ese año no hubo acuerdo legislativo para una nueva prórroga y la ley quedó sin efecto. En octubre de 2014 los diputados porteños aprobaron la protección de 1.700 inmuebles. Las organizaciones de protección patrimonial presentaron un amparo para proteger el resto de los inmuebles anteriores a 1941, esto llevó al Gobierno porteño a encargar a la Facultad de Arquitectura un relevamiento de edificios de valor patrimonial. ${ }^{14}$

En el año 2016 la Justicia ordenó que no se otorguen autorizaciones o permisos para demoler, reformar o ampliar edificios construidos antes del 31 de diciembre de 1941 o cuyos planos hayan sido registrados antes de esa fecha, a menos que una evaluación previa determine si la edificación tiene valor patrimonial. Los permisos podrán otor-

\footnotetext{
13. Para cada uno de estos bienes hay una descripción que contiene indicaciones esenciales: ubicación datos catastrales y de parcelas, propietario, tipo de edificio (retiro, altura de la construcción, etc.), el estilo y la tipología arquitectónica, el material y la técnica constructiva, el uso histórico y actual; el trabajo se completa con información gráfica y fotográfica. Las descripciones no incluyen anotaciones sobre el estado de conservación del objeto.

14. El trabajo detectó 3.207 inmuebles que fueron incorporados preventivamente al catálogo de inmuebles protegidos.
} 


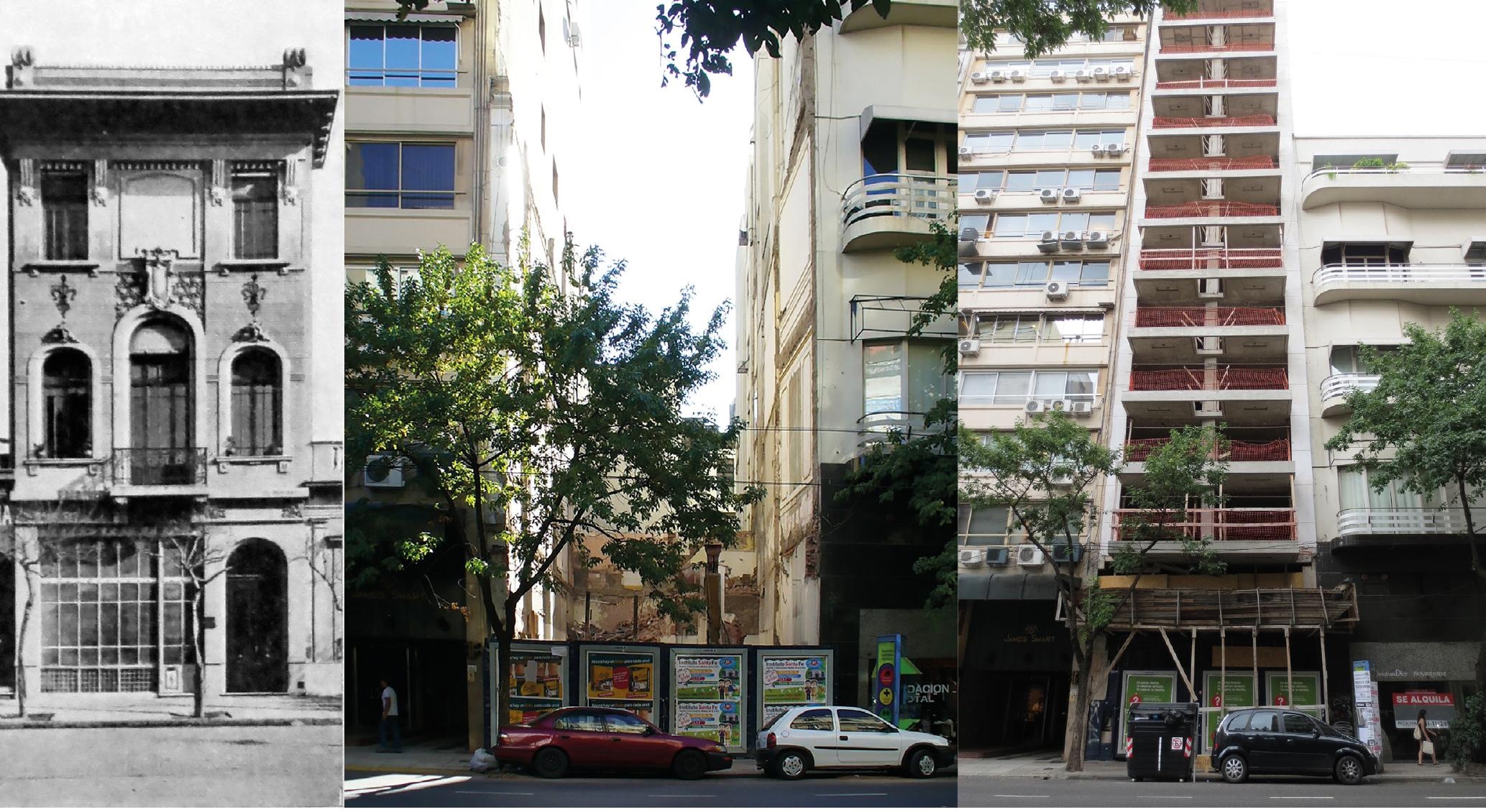

Figura 11. Buenos Aires, Argentina, Petit Hotel, Arq. L. Broggi. Ejemplo de demolición y nueva construcción. Foto a la izquierda: Scardin F. (1906). La Argentina y el trabajo, Buenos Aires, Argentina: J. Peuser. Fotografia central 2009 y derecha 2015: Machado. garse sólo si el Consejo Asesor de Asuntos Patrimoniales ha resuelto previamente, en forma expresa e individualizada, que el edificio no tiene valor patrimonial.

\section{Observaciones sobre la eficacia de la legislación de tutela vigente}

Aunque en las últimas décadas se advirtió una mayor atención por lo que se refiere al patrimonio arquitectónico, la implementación de la estructura legislativa evidencia problemas, a menudo bastante complejos, que pueden subdividirse en tres grandes categorías (institucional, socio-económico y cultural-formativo) con contenidos que a veces se sobreponen. Problemáticas que conducen a procedimientos burocráticos complejos y largos que, junto con los grandes intereses económicos, han generado importantes transformaciones edilicias favorecidas por una política económica neoliberal y facilitadas por el conjunto de las normativas de planificación urbana que conducen a promover el reemplazo de edificios como criterio para la reconfiguración urbana. Situación agravada aún más por la insuficiente capacitación de arquitectos y técnicos que deben operar en este ámbito y que ha llevado a la pérdida parcial o total de varios edificios, con alteraciones que afectan la calle, la cuadra, el barrio, hasta porciones enteras del aglomerado urbano, por lo tanto, de una porción importante del patrimonio arquitectónico de la ciudad (ver Figura 12).

En la Ciudad Autónoma de Buenos Aires la presión económica que sufre el tejido urbano, además de las normas urbanísticas obsoletas, tiende a impulsar a los propietarios a demoler, reconstruir o elevar sus edificios con el propósito de aumentar las superficies habitables. Las normas edilicias que conciernen a las áreas históricas de la ciudad a menudo resultan inadecuadas por ser demasiado genéricas y tendientes a banalizar las relaciones con el contexto construido, favoreciendo la destrucción del patrimonio histórico (para reemplazarlo por inmuebles más altos y voluminosos) y contribuyendo a su empobrecimiento. Un ejemplo es la transformación del "Palacio Costaguta" (19031907), consecuencia de la obligación de uniformar las construcciones que miran a la Plaza Lavalle a una altura de alero predefinida. Obligación que contradice una de las características del tejido histórico urbano que se manifiesta en alturas y volumetría diferenciadas (ver Figura 13). 
Este edificio había sido proyectado por el arquitecto francés Alfred Massüe y fue elegido entre las obras arquitectónicas merecedoras del "Premio Municipal de Fachadas". Era una construcción de cuatro pisos, más subsuelo, entrepisos y áticos, con espacios comerciales y viviendas. En 1989 se llevaron a cabo obras de renovación que condujeron a la demolición parcial y a la transformación del edificio, desnaturalizando el diseño original. El nuevo proyecto, que presenta superficies de vidrio de 12 pisos de altura, conserva solo el esqueleto de la torre de la esquina. La intervención agradó mucho a las autoridades que confirieron un reconocimiento a los proyectistas por la "voluntad de conservación del patrimonio arquitectónico urbano y por el apreciable aporte a la memoria ciudadana" (ver Figura 14).

Un ejemplo emblemático es la destrucción de la "Sede Central del Banco Español del Río de la Plata" (1905), un importante testimonio Beaux-Arts de la arquitectura bancaria del centro histórico (ver Figura 15), elemento fundamental del paisaje urbano y complemento inseparable de la Iglesia de la Merced y del ex Banco de Londres, Monumentos Históricos Nacionales. Aunque se le reconoció un valor histórico, pero sin soporte legal, en el año 2000 fue demolido y sustituido por una torre de oficinas de 160 metros. El proyecto, aprobado por la Secretaría de Planeamiento urbano de la Ciudad de Buenos Aires ya que fue considerado un gran aporte al paisaje urbano del microcentro, fue aceptado porque la torre conservó dos pequeños fragmentos que pertenecieron al viejo edificio, elementos que hubieran "dado valor al área conservando el recuerdo del edificio". Juicio dado por las autoridades (Sociedad Central de Arquitectos y el Centro Internacional para la Conservación del Patrimonio) y que le valió el premio nacional a la mejor intervención en edificios de valor patrimonial ${ }^{15}$ al arquitecto Mario Roberto Alvarez, autor del proyecto (ver Figura 16).

El edificio (Banco de Galicia) ubicado detrás de la Catedral de Buenos Aires (Monumento Histórico Nacional), es claramente visible desde la Plaza de Mayo y desde los monumentos que rodean la plaza (Casa Rosada y Cabildo). El edificio, de 33 pisos de altura, rompe la composición arquitectónica del lugar, dejándola fragmentada. El banco aparece como un elemento disonante en la escala urbana, donde todos los edificios tienen una dimensión y una materialidad en relaciones armoniosas (ver Figura 17).

Estos ejemplos son el resultado de la aplicación de las leyes promulgadas a lo largo de los años. Leyes que llevaron a una fuerte alteración, si no a la destrucción, del tejido urbano histórico, porque sustancialmente falta una integración correcta entre lo antiguo y lo nuevo. En efecto, a menudo, los nuevos edificios contrastan con lo existente, sin buscar un diálogo armónico con el pasado, es decir, sin ocultar lo existente y sin perder la autenticidad de lo nuevo. Esto sucede por la falta de un conocimiento adecuado del contexto urbano (edificios y lugares) en todos los niveles (político, profesional, etc.), y principalmente debido a la falta de conciencia sobre el valor de los recursos disponibles, y como dice Salvatore Settis "[...] de la irreversibilidad de su consumo" tanto por parte de los ciudadanos como por parte de una clase política poco propensa a la protección del patrimonio histórico-cultural de nuestro pasado. Una clase dirigente, política y económica que entiende "[...] el paisaje y el ambiente no [...] como un valioso 'capital territorial' que no hay que desperdiciar porque es irreemplazable, sino como una especie de estorbo, un peso muerto del cual hay que librarse a través de operaciones especulativas" (Settis, 2010, p. 43) (ver Figura 18).

Desgraciadamente, en estos últimos años las cosas no han cambiado mucho, como atestigua una serie de demoliciones de pequeños inmuebles (petit hotel-construcciones de comienzos del 900-, casas de renta, casonas, etc.) cuya causa principal fue la ex-

15. Grementieri F., Emergencia patrimonial en Argentina. Pedido de asistencia internacional, informe elevado al Comité de Patrimonio en Peligro del Icomos Internacional. 


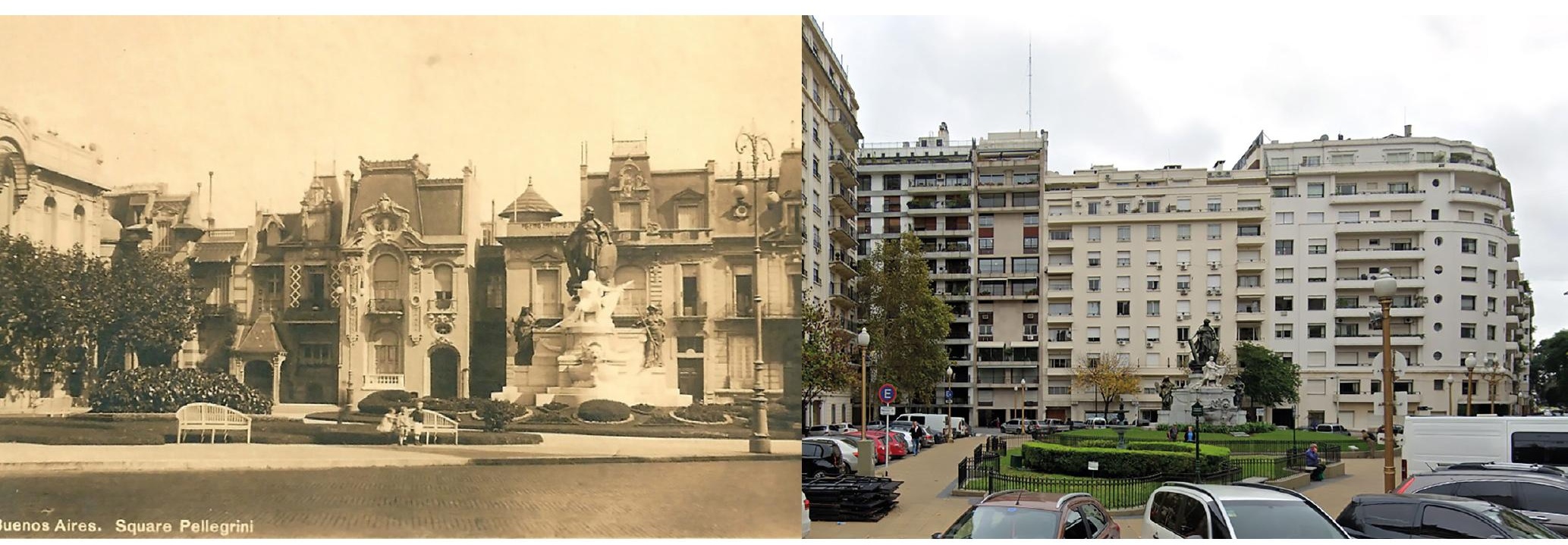

Figura 12. Plaza Carlos Pellegrini, Buenos Aires, Argentina. Arriba, Petit hotel en una postal de inicio siglo XX. Abajo, foto actual. Gobierno de la ciudad de Buenos Aires, 2018.

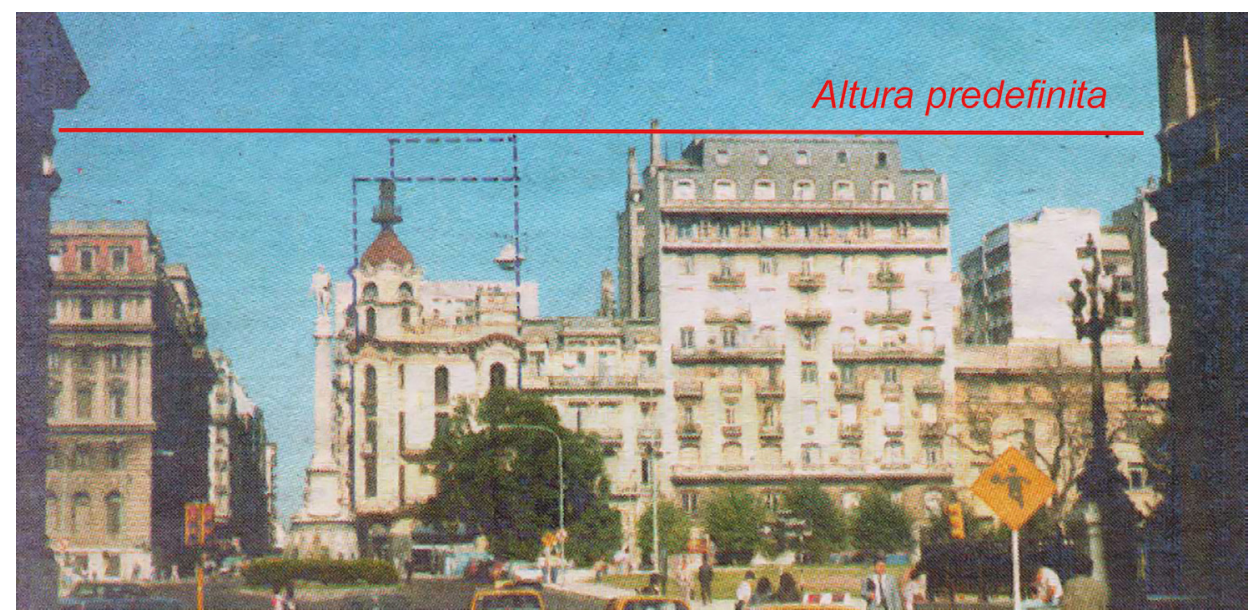

Figura 13. Plaza Lavalle con Palacio Costaguta con la indicación de la altura obligatoria al fin de uniformar las construcciones según el Código de Planificación Urbana. Archivo del Diario Clarín, 2008.

trema densificación urbana, instrumento para "la reactivación del sector inmobiliario" (ONG Basta de demoler).

Otro problema se detecta en la aplicación de las normas, ya que con frecuencia los edificios históricos que se deben recuperar no cumplen con los estándares de edilicios/tecnológicos requeridos por el Código de Planeamiento actual. Esto lleva a intervenciones drásticas, destruyendo la originalidad y las cualidades arquitectónicas de la obra.

Mediante la promulgación de algunas leyes el gobierno ha causado problemas y daños a edificios antiguos. Esto es lo que sucedió con la ley $257 / 99$ (reglamento de 2000) y sus respectivas modificaciones con la ley $6.116 / 18$ que regula la seguridad de fachadas, balcones, terrazas y azoteas dentro de la ciudad. Esta norma obliga a una inspección técnica específica del estado de los elementos de fachada con una periodicidad dependiente de la antigüedad del edificio (cada 4 años todos los edificios de más de 70 años; cada 


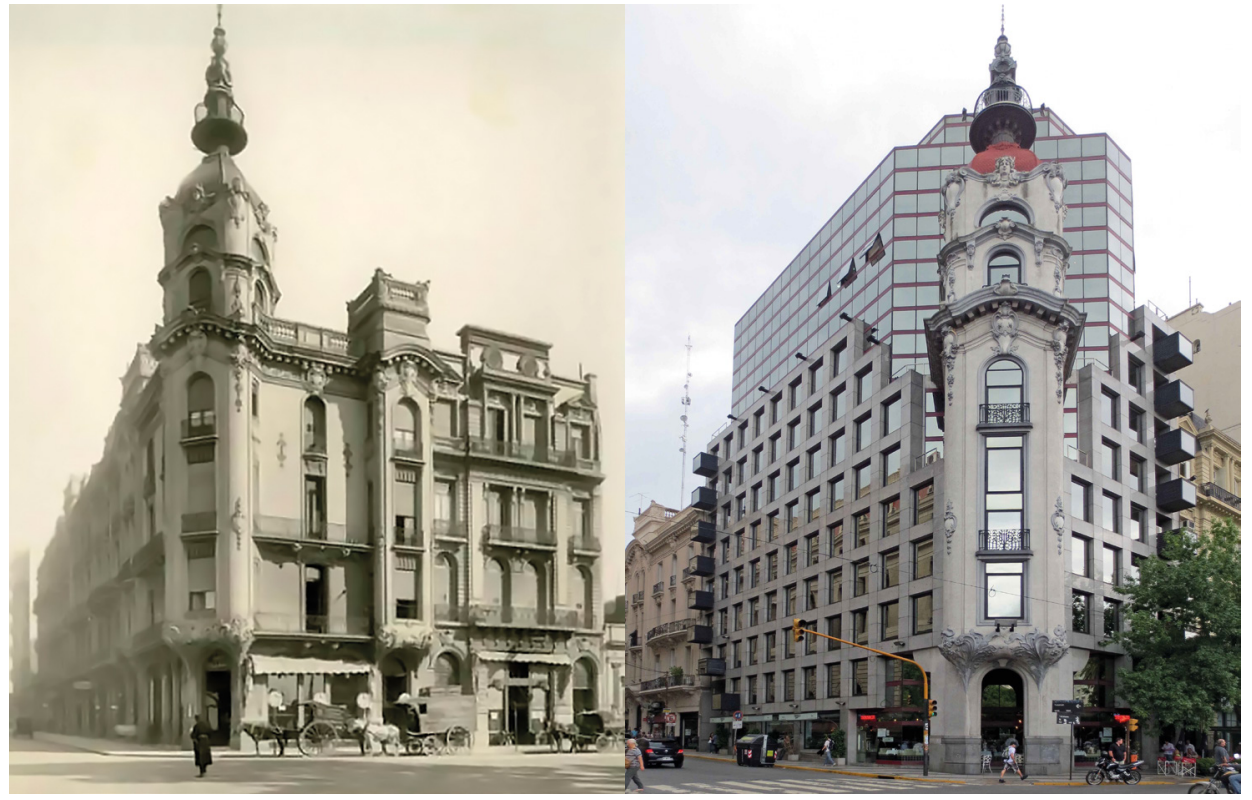

5 años para todos los edificios entre 55 y 69 años, etc.), sin establecer la calificación de los profesionales que deben realizar la inspección (no necesariamente especialistas en conservación y restauración). Los controles se llevan a cabo de forma visual y a menudo a distancia, consecuentemente, para garantizar la seguridad del edificio, a menudo se requiere la eliminación de la ornamentación y de todas las partes que sobresalen, desnaturalizando el aspecto y la calidad arquitectónica de las fachadas. Esto se debe a que el legislador ha olvidado contemplar el valor cultural y/o histórico del objeto al reglamentar los métodos de intervención (ver Figura 19).

La pérdida total o parcial de estos edificios implica la alteración del entorno, así como las características que definen una calle, una cuadra, un barrio hasta llegar a toda la ciudad. Además, el daño causado a la comunidad en su conjunto es inconmensurable al enfrentarse a una privación o daño irreparable. Es por tal motivo que la tutela y conservación de los bienes arquitectónicos se vuelve esencial. Como afirma Bernhard Furrer ${ }^{16}$, "el patrimonio en su conjunto nos proporciona una base sobre la cual podemos entender de dónde venimos y hacia dónde podemos ir. [...] En su conjunto el patrimonio construido es testigo de nuestra historia; su presencia en nuestra vida cotidiana nos acompaña, nos asegura estabilidad. Representa un bien de la comunidad entera". Por lo tanto, debemos tutelarlo como tal y garantizar su protección y preservación que debe focalizarse en la comprensión de la obra y de su connotación histórica, como así también en el reconocimiento e interpretación de los valores de los que es portadora, en la identificación y definición del papel que desempeña en la sociedad y de los mecanismos de recepción, uso y transmisión que la arquitectura encarna dentro de los valores del mundo contemporáneo. Por lo tanto, intervenir sobre estos edificios significa tener que realizar, como afirma Amedeo Bellini:

[...] un progetto d'architettura che si applica a una preesistenza, compie su di essa tutte le operazioni tecniche idonee a conservarne la consistenza materiale, a ridurre i fattori estrinseci di degrado, per consegnarla alla fruizione come strumento di soddisfazione dei bisogni, con le alterazioni strettamente indispensabili, utilizando studio preventivo e progetto come strumenti d'incremento della conoscenza.

16. Bernhard Furrer fue presidente de la Comisión Federal Suiza de los Monumentos Históricos. Entrevista en el blog parcodivillaargentina.over-blog.it

Figura 14. Palacio Costaguta (19031907), arq. A. Massüe, Buenos Aires, Argentina. A la izquierda, fotografia de inicio siglo XX. A la derecha, fotografia actual con la trasformación de 1989. Archivo General de la Nación Argentina y archivo fotográfico de la autora, 2018. 


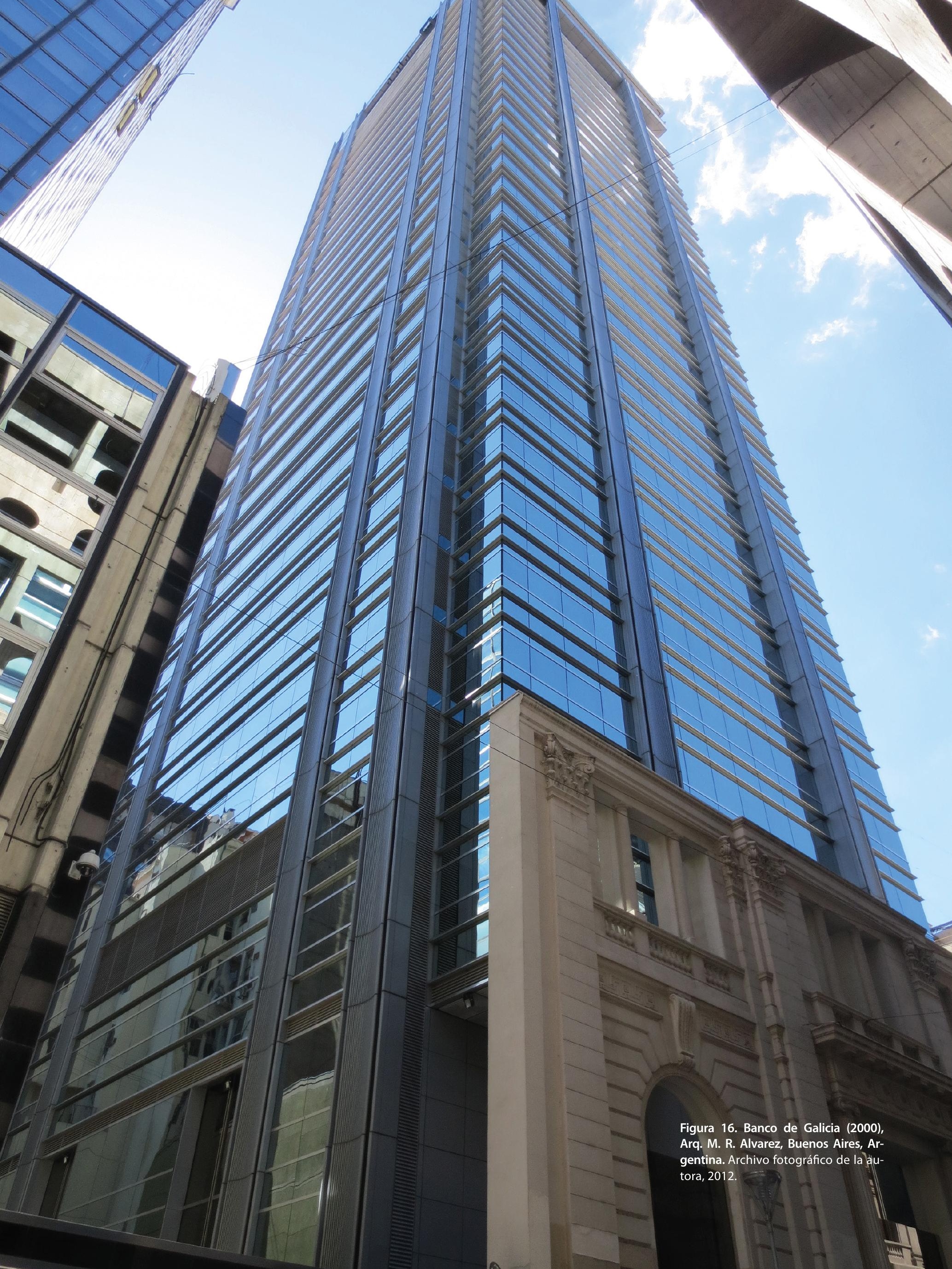


devenir Vol. 7, N¹4, JULIO-DICIEMBRE 2020, PP. 131-154 - EstudIOS I ISSN 2312-7562 I E-ISSN 2616-4949

UNIVERSIDAD NACIONAL DE INGEEIERÍA, LIMA

doi: https://doi.org/10.21754/devenir.v7i14.974

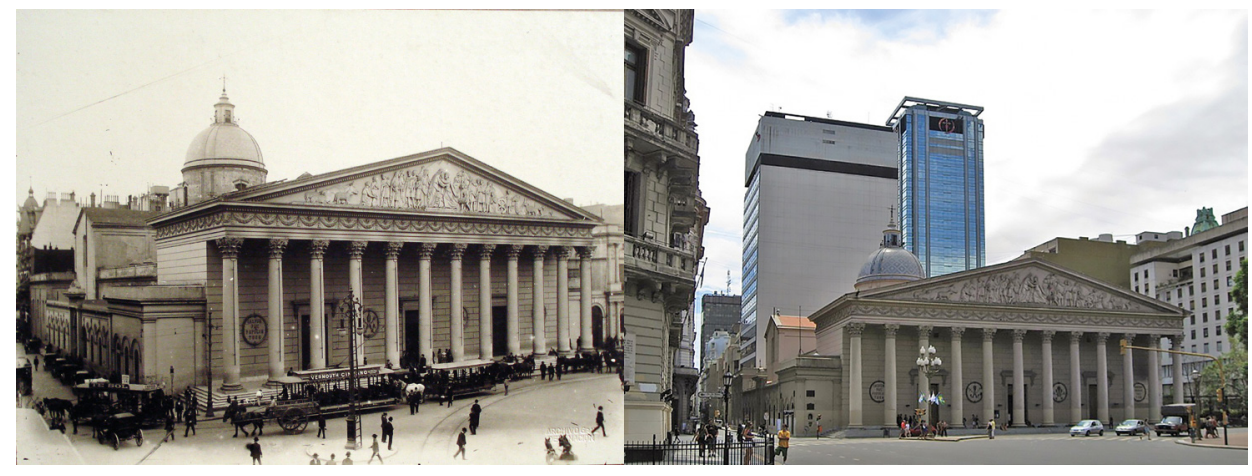

Figura 17. Catedral de Buenos Aires, Argentina. A la izquierda en una fotorgrafia de inicio siglo XX. A la derecha Banco de Galicia (2000) a espaldas de la Catedral de Buenos Aires. Archivo Witcom y archivo fotográfico de la autora, 2018.

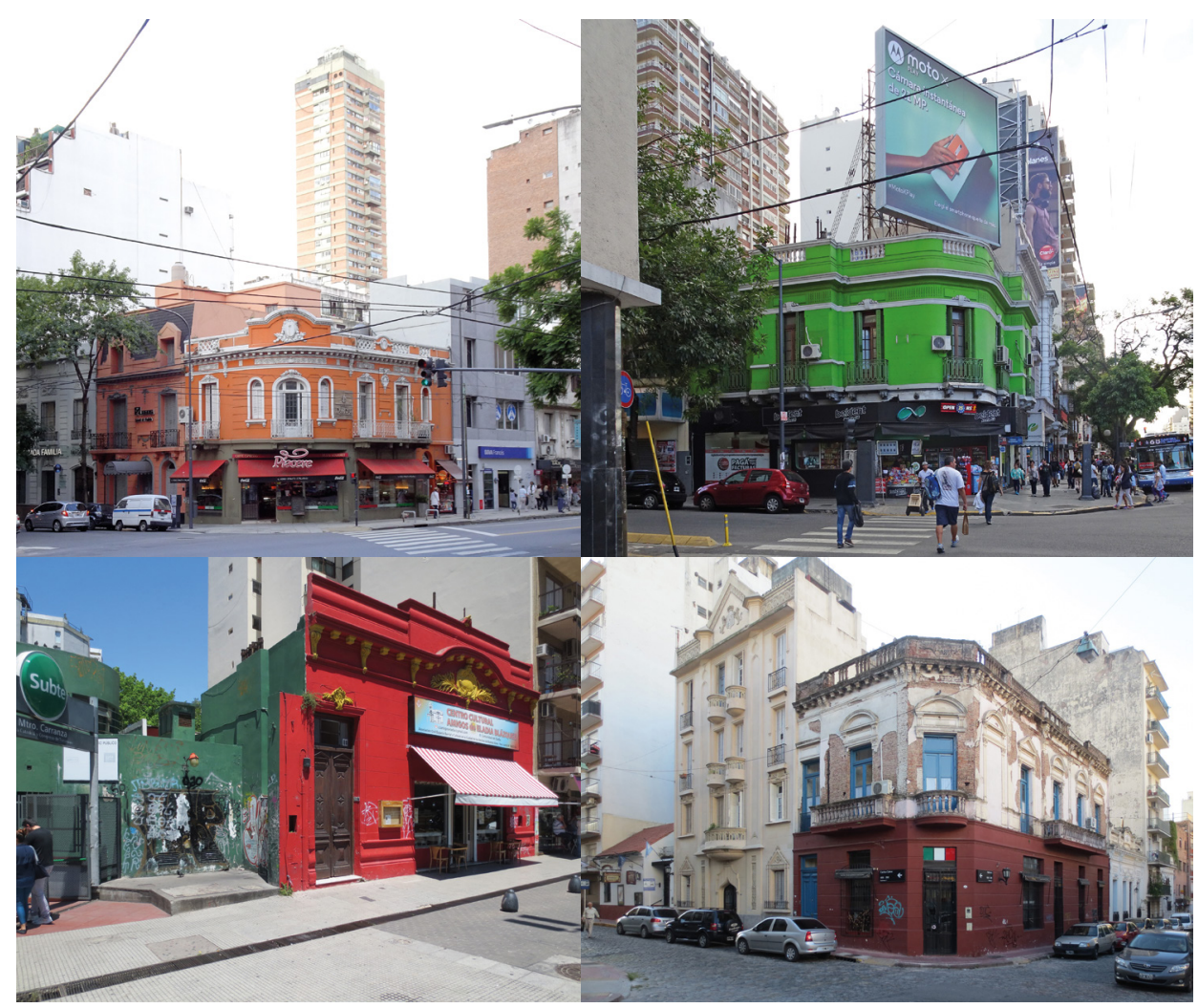

Figura 18. Buenos Aires, Argentina, ejemplos de mala intervención en edificios históricos. Archivo fotográfico de la autora, 2018.

La gestión de los servicios de tutela deberá establecer y perseguir diversos objetivos: la unidad en la planificación y en los programas; la homogeneidad de criterios y métodos de tutela y conservación; una acción de tutela continua, equilibrada y difusa; la eficiencia técnica y el conocimiento de las tipologías; la promoción cultural y didáctica en una perspectiva de educación permanente de los ciudadanos.

Sería deseable, además, promover el interés de las autoridades para la salvaguardia de los bienes arquitectónicos; coherencia, pluridisciplina y cooperación por parte de las autoridades; formación de figuras profesionales especializadas; educación a todo nivel para difundir la cultura sobre la tutela de los bienes arquitectónicos; información y participación de la población en el proceso de aplicación de la tutela; desarrollo de 


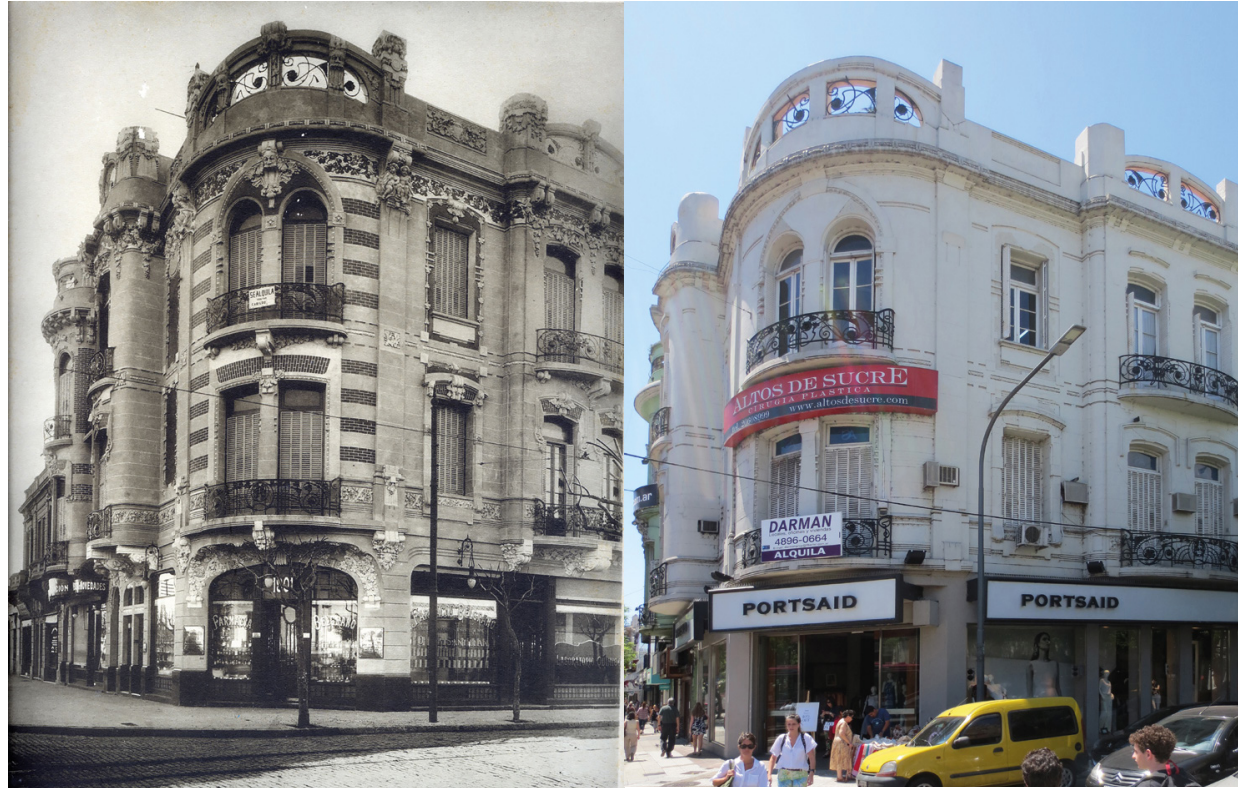

acciones de sensibilización, información y comunicación. La colaboración internacional podría ayudar a mejorar la actual situación mediante el aporte de organismos o países qué estén en la vanguardia en estos temas.

Para concretar las mejores y más correctas estrategias de integración en la estructura territorial, con el fin de no perder la identidad del lugar, surge la necesidad de una planificación urbana coordinada que permita el desarrollo de la ciudad en el respeto de las áreas APH y de los edificios protegidos de forma individual. El edificio tutelado se debe poder integrar en el contexto del entorno construido para que pueda vivir relacionándose armoniosamente con el inevitable desarrollo del aglomerado urbano.

La integración de la planificación urbana con la protección del patrimonio arquitectónico es una cuestión de suma importancia si no se quiere perder la identidad de un lugar. Esto también evita detener la lenta destrucción del patrimonio histórico-cultural y la consecuente dificultad en sentirlo parte integrante de la propia experiencia de la comunidad.

Un buen gobierno, sumado a una virtuosa práctica proyectual con una formación especializada para proyectos sobre bienes arquitectónicos, son la base necesaria e indispensable para el logro de una eficiente política de tutela. Todo ello con el propósito de salvaguardar y transmitir adecuadamente a las generaciones futuras el rico patrimonio arquitectónico de cada país.

Recordemos que el patrimonio arquitectónico es, y debe ser considerado, un recurso común y como tal, su protección es responsabilidad de todos los ciudadanos.

\section{Referencias}

AA.VV. (2004). Un paisaje cultural excepcional. Buenos Aires, Argentina: Ministerio de Cultura.

Aliata, F. y Liernur, F. (Coords.) (1992). Diccionario Histórico de Arquitectura, Hábitat y urbanismo en la Argentina. (ed. preliminar). Buenos Aires, Argentina: Proyecto Editorial.

Basile, S. (2010). Politiche di conservazione e tutela dei beni architettonici nella città di Buenos Aires e prospettive di recupero per il barrio La Boca. (Tesis doctoral). Italia: Politecnico di Milano.

Basile, S. (2013). Politiche di tutela e conservazione dei beni architettonici nella Repubblica Argentina. La città di Buenos Aires. Sant'Arcangelo di Romagna. Italia: Maggioli Editore.

Basile, S. (2017). Salvaguardia y valorización del Patrimonio Modesto porteño producido a fines del siglo XIX. En El patrimonio cultural como testimonio. Nuevos paradigmas para su concep-
Figura 19. Edificio de Domingo Brignoni, Arq. B. Pedrotti, en avenida Cabildo, Buenos Aires, Argentina. A la izquierda en una fotografia de inicio siglo XX. A la derecha foto actual. Archivo General de la Nación Argentina y archivo fotográfico de la autora, 2018. 
devenir Vol. 7, N¹4, JULIO- DICIEMBRE 2020, PP. 131-154 - EsTUDIOS | ISSN 2312-7562 | E-ISSN 2616-4949

UNIVERSIDAD NACIONAL DE INGGENIERÍA, LIMA

doi: https://doi.org/10.21754/devenir.v7i14.974

ción, 17-24. Buenos Aires, Argentina: Instituto de Arte Americano e Investigaciones Estéticas Mario J. Buschiazzo: www.iaa.fadu.uba.ar/ppci

Bellini, A. (ed.). (1996). Tecniche della conservazione. Milano, Italia: Franco Angeli.

Buschiazzo, M. (1959). Argentina: monumentos históricos y arqueológicos. México: Instituto Panamericano de Geografía e Historia.

Buschiazzo, M. (1967). La arquitectura en la Argentina. Buenos Aires, Argentina: Filmediciones Valero, Librería del Colegio.

Buschiazzo, M. (1996-1997). La destrucción de nuestros monumentos históricos. Anales del Instituto de Arte Americano e Investigaciones Estéticas Mario J. Buschiazzo, 31-32. Buenos Aires, Argentina: Instituto de Arte Americano e Investigaciones Estéticas "Mario J. Buschiazzo".

Código de Planificación Urbana. (2000) Ley 449.

Constitución de la Ciudad Autónoma de Buenos Aires. (1996 octubre). Boletín Oficial de la ciudad. Constitución de la Nación Argentina (1994), CEDOM, ed. Concejo Deliberante.

Comisión Nacional de Museos Monumentos y Lugares Históricos. (1941). Ley 12.665 sobre museos, monumentos y lugares históricos. Buenos Aires, Argentina: Author.

Comisión Nacional de Museos Monumentos y Lugares Históricos. (1996). Monumentos históricos de la República Argentina. Buenos Aires, Argentina: Fondo Nacional de las Artes, Dirección Nacional de Arquitectura, Secretaría de Cultura.

Comisión Nacional de Museos Monumentos y Lugares Históricos. (2001). Patrimonio, memoria y proyecto. 1995-2001. Buenos Aires, Argentina.

Comisión para la Preservación del Patrimonio Histórico Cultural de la Ciudad de Buenos Aires. (ed.). (1999). Temas de Patrimonio Cultural II. Buenos Aires, Argentina: Gobierno de la Ciudad de Buenos Aires.

Comisión para la Preservación del Patrimonio Histórico Cultural de la Ciudad de Buenos Aires. (ed.). (2000). Nuevas perspectivas del Patrimonio Histórico Cultural de la Ciudad de Buenos Aires. Buenos Aires, Argentina: Comisión para la Preservación del Patrimonio Histórico Cultural de la Ciudad de Buenos Aires.

Comisión para la Preservación del Patrimonio Histórico Cultural de la Ciudad de Buenos Aires. (ed.). (2000). Patrimonio e identidad cultural. Buenos Aires, Argentina: Comisión para la Preservación del Patrimonio Histórico Cultural de la Ciudad de Buenos Aires.

Dirección de Museos, Monumentos y Lugares Históricos. (ed.). (s.f.). Catálogo de museos, monumentos y lugares históricos. Provincia de Buenos Aires y Capital Federal. Buenos Aires, Argentina: Subsecretaría de Cultura.

Gobierno de la Ciudad de Buenos Aires (ed.). (2000). Plan Urbano Ambiental. Documento final. Buenos Aires, Argentina.

Gobierno de la Ciudad de Buenos Aires (ed.). (2006). Paisaje cultural de Buenos Aires. El río, la pampa, la barranca y la inmigración. Buenos Aires, Argentina: Author.

Gobierno de la Ciudad de Buenos Aires, Secretaría de Planeamiento Urbano del Gobierno de la Ciudad de Buenos Aires, Facultad de Arquitectura, Diseño y Urbanismo de la Universidad de Buenos Aires. (eds.). (s.f.). Áreas de Protección Histórica. Buenos Aires, Argentina: Author.

Gomes, M. y Zunino, D. (2008). La (re)valorización de la zona sur y su patrimonio histórico-cultural como recurso turístico. En Herzer, H. (ed.), Con el corazón mirando al Sur. Transformaciones en el sur de la ciudad de Buenos Aires. Buenos Aires, Argentina: Espacio Editorial.

Grementieri, F. (s.f.). Emergencia patrimonial en Argentina. Pedido de asistencia internacional, informe elevado al Comité de Patrimonio en Peligro del Icomos Internacional.

Grementieri, F. y Verstraeten, X. (2005). Buenos Aires: Arquitectura y Patrimonio. Buenos Aires, Argentina: Ediciones Xavier Verstraeten.

Petrina, A. (ed.). (1994). Buenos Aires. Guía de Arquitectura. Buenos Aires, Argentina: Junta de Andalucía.

Settis, S. (2010). Paesaggio Costituzione Cemento. La battaglia per l'ambiente contro il degrado civile. Torino, Italia: Einaudi.

Torsello, B. P. (ed.). (2005). Che cos'è il restauro? Nove studiosi a confronto. Venezia, Italia: Marsilio. 